2 Xihui Gu ${ }^{1,2,3}$, Qiang Zhang ${ }^{4,5,6^{*}}$, Jianfeng $\mathrm{Li}^{2}$, Jianyu Liu ${ }^{7}$, Chong-Yu Xu ${ }^{8}$, Peng

\section{The changing nature and projection of floods across Australia}

$\operatorname{Sun}^{9}$

1. Department of Atmospheric Science, School of Environmental Studies, China University of Geosciences, Wuhan 430074, China;

2. Department of Geography, Hong Kong Baptist University, Hong Kong, China;

3. State Key Laboratory of Loess and Quaternary Geology, Institute of Earth Environment, CAS;

4. Key Laboratory of Environmental Change and Natural Disaster, Ministry of Education, Beijing Normal University, Beijing 100875, China;

5. Faculty of Geographical Science, Academy of Disaster Reduction and Emergency Management, Beijing Normal University, Beijing 100875, China;

6. State Key Laboratory of Earth Surface Processes and Resource Ecology, Beijing Normal University, Beijing 100875, China;

7. Laboratory of Critical Zone Evolution, School of Earth Sciences, China University of Geosciences, Wuhan 430074, China;

8. Department of Geosciences and Hydrology, University of Oslo, P O Box 1047 Blindern, N-0316 Oslo, Norway;

9. College of Territorial Resource and Tourism, Anhui Normal University, Anhui 241002, China.

Corresponding author*: Qiang Zhang (zhangq68@bnu.edu.cn) 
Abstract: Changes in peak magnitude, volume, frequency and duration of floods obtained from a peak-over-threshold sampling in 780 unregulated catchments show significant differences between northern and southern Australia over 1975-2012. Increases of the flood properties are mainly located in northern Australia, while decreases are mostly in southern Australia. These changes could be dominated by inter-annual and/or decadal variability of floods. The multidimensional behaviors of flood change across Australia can be described by three distinct groups (i.e. no changes, increases and decreases in all flood properties), showing strong geographic cohesion. The geographical consistency between the changing patterns of flood properties and spatial patterns of vapor transport anomalies during the El Niño-Southern Oscillation (ENSO) positive phase could partly explain the geographic cohesion of flood changes. In a warmer future, the observed decreases in floods in southern Australia are projected to continue with high model agreement, while only magnitude and volume of floods in northern Australia are projected to increase but with high uncertainties. The diametric changes in flood magnitude between northern and southern Australia are projected to be more evident in extreme (i.e. 50-year) floods than small (i.e. 5- and 20-year) floods.

Key words: Flooding behaviors; Flood magnitude, Flood volume; Flood frequency; Flood prediction

\section{Introduction}


In Australia, floods cause more loss of life than any other disasters (FitzGerald et al., 2010). The economic damage and loss caused by floods are equivalent to more than \$400 million per year (Bureau of Meteorology, 2009). Recently, Australia has been plagued by a series of extreme floods such as those occurred in 2011 and 1974 which led to economic losses reaching millions of dollars (Box, et al., 2013). However, the question remains: are the characters of flooding truly changing under climate change?

Climate change considerably affects various aspects of the hydrologic cycle (Allen and Ingram, 2002; Zhang et al., 2017). The amplified hydrologic cycle results in more frequent and extreme floods (Hirabayashi et al., 2013; Winsemius et al., 2016). Numerous recent studies have been carried out to explore impacts of climate change on flooding in many parts of the world based on observations and/or model simulations, such as China (e.g., Zhang et al., 2014; Li et al., 2016), the United States (e.g., Mallakpour and Villarini 2015; Archfield et al., 2016), Europe (e.g., Berghuijs et al., 2017; Blöschl et al., 2017), as well as Australia (Halgamuge et al., 2017; Liu et al., 2017). However, studies may draw different and even contradictory conclusions about changes in flooding in the same region (Mallakpour and Villarini 2015; Archfield et al., 2016). For example, Mallakpour and Villarini (2015) reported cohesively increasing trends in flood frequency over central United States, while the trends in the same region detected in Archfield et al. (2016) were fragmented. The reports of Intergovernmental Panel on Climate Change (IPCC) indicated that "there continues to be a lack of evidence and thus low confidence regarding the sign of trend in the 
magnitude and/or frequency of floods at a global scale” (IPCC, 2013). Low confidence in flood changes under global warming is mainly due to limited observations and the complex surface hydrologic processes in regions. The sophisticated interactions between climatic (e.g., tropical cyclones, organized thunderstorm systems, and extratropical systems) and anthropogenic factors (e.g., population, land use, and infrastructure) is a major type of the complexity (Johnson et al., 2016) which makes examination of changes in flooding caused by climate change with reasonable accuracy a huge challenge (Merz et al., 2012).

The spatial and temporal aspects of flood variability in Australia are also connected to the impacts of large-scale climate indices. Several climate indices, such as El Niño-Southern Oscillation (ENSO), Indian Ocean Dipole (IOD), Southern Annular Mode (SAM), and Interdecadal Pacific Oscillation (IPO), were recognized to have important impacts on climate variability in Australia (Pui et al., 2012; Min et al., 2013; Liu et al., 2018a). Linear trends in precipitation during 1981-2014 were largely attributable to ENSO and IOD across Australia (Forootan et al., 2016). Summer precipitation extremes in eastern Australia are associated with SAM, and this region tends to be wetter and cooler during the positive phase of SAM (Min et al., 2013). On a multidecadal timescale, compared with the negative phase of IPO, the climate in Australia tends to be "drier" during the positive phase of IPO (Verdon and Wyatt, 2004). IPO also tends to modulate the relation between ENSO and Australian climate variability (King et al., 2013). The impacts of IOD, SAM, and IPO on climate variability are recognized across Australia; however, ENSO is identified as the 
dominant driving factor behind climate variability over Australia (Pui et al., 2012). Liu et al. (2018a) analyzed the relations between flood variability and the four climate indices mentioned above, and confirmed that Australian flood variability is heavily influenced by ENSO. Wasko et al. (2015) developed the Randomized Bartlett Lewis model considering the impact of ENSO in the continuous stochastic precipitation simulation in Australia, and then replicated observed wet spell statistics and catchment antecedent conditions.

Previous studies investigated Australian floods caused by climate change usually using annual maximum series (AMS) and without separating the effects of human activities (e.g., Villarini et al., 2012; Rouillard et al. 2015; Halgamuge et al., 2017). The AMS defined as the largest streamflow occurring in a year only reflects the changes in magnitude of the annual maximum flood. If there are several floods in one year, only one flood event is considered in AMS. However, in reality, it may happen that the highest flow in a year is not extreme enough to be a flood event, but it is still considered in AMS. There may be more than one flood events in a year, but only the largest flood can be included in AMS. Additionally, the low confidence that climate change has affected the frequency and magnitude of fluvial floods is mainly due to a lack of long-term records from unmanaged catchments (IPCC, 2014).

Therefore, in this study, flood records of more than 30 years from 780 unregulated catchments across Australia are used to investigate changes in peak magnitude, volume, frequency and duration of flood events across the various physiographic and climate regions of Australia. A peak-over-threshold (POT) 
111 sampling method which can break the limitations of AMS is used to obtain the four

112 flood characteristics and then to identify distinct groupings of multidimensional flood

113 behaviors. To the best of our knowledge, no previous studies have used the POT

114 approach to characterize the flood characteristics and examine multivariate flood

115 properties for the widespread unregulated catchments in Australia. Evaluating the

116 changes in multivariate flood properties is beneficial for us to address questions such

117 as whether floods are becoming more frequent, longer, or larger in current conditions

118 and warmer future.

\section{Data}

\subsection{Observations from the 780 unregulated catchments} desert areas, daily discharge data (unit: $\mathrm{m}^{3} / \mathrm{s}$ ) from 780 unregulated and unimpaired catchments across Australia covering the 1975-2012 period were collected from respective state water agencies (Zhang et al., 2013). These 780 catchments were selected from more than 4,000 catchments across Australia using four selection criteria: (1) the catchment area is greater than $50 \mathrm{~km}^{2}$; (2) the stream is unregulated, i.e. not subject to dam or reservoir regulations; (3) the catchment is unimpaired, i.e. not subject to major impacts of irrigation and intensive land use; and (4) the observed

131 discharge record contains at least 3,652 daily observations (equivalent to ten years) during 1975-2012 with acceptable data quality according to a consistent national 
standard. Missing values in the discharge dataset were filled by the best simulation obtained from three calibrated hydrological models: Xinanjiang, SIMHYD and AWRA models (Zhang and Chiew, 2009; Zhou et al., 2013; Zhang et al., 2016). For each catchment, the best model is identified by the highest Nash-Sutcliffe Efficiency (NSE) among the three models. We extracted the NSE value of the optimal model simulations for each catchment, and then obtained a series of 780 NSE values. The 10th, 50th, and 90th of the 780 NSE values are $0.43,0.67$, and 0.81 , respectively, suggesting an acceptable performance of the optimal model simulations (Liu and Zhang, 2017). Zhang and Post (2019) evaluated the ability of hydrological models for gap filling by taking this discharge dataset for experiments, indicating that the gap filling of hydrological models is very reasonable and has little impact on discharge trend. More details on this dataset can refer to the report of Zhang et al. (2013) entitled “Collation of Australian modeller's streamflow dataset for 780 unregulated Australian catchments".

In addition to daily discharge data, we also collected the catchment information and catchment attributes of these 780 basins, including daily precipitation, daily evapotranspiration, percentage of irrigation land use and intensive land use (Fig. S1). The daily evapotranspiration at a $5 \mathrm{~km}$ spatial resolution was estimated using the Priestley-Taylor equation (Eichinger et al., 1996) with inputs of 5-km gridded climate dataset including daily maximum temperature, daily minimum temperature, daily solar radiation and daily vapor pressure. The $5-\mathrm{km}$ gridded meteorological data in Australia are sourced from SILO (http://www.longpaddock.qld.gov.au/silo/) and 
AWAP (http://www.bom.gov.au/climate/data/). It is difficult to adequately characterize the catchment precipitation in catchments smaller than about $50 \mathrm{~km}^{2}$ in drainage area using such coarse gridded data. The statistical summary of the catchment attributions in each climatic region is shown in Table 1.

\subsection{Modeled discharge data}

In this study, the future changes of floods were also evaluated using simulated daily discharges from eight hydrological models (HMs) forced by five Coupled Model Intercomparison Project Phase 5 (CMIP5) global climate models (GCMs) from the Inter-Sectoral Impact Model Intercomparison Project (ISI-MIP) (Table 2 and 3). In ISI-MIP, each HM is driven by the bias-corrected outputs of the five CMIP5 GCMs. ISI-MIP has been widely used to evaluate the responses of hydrology, meteorology, and agriculture to future warming climate (e.g., flood, drought, water availability) (Li et al., 2016; Asadieh and Krakauer 2017; Frieler et al., 2017).

Due to the coarse resolutions of the GCM outputs, they are bias corrected into a uniform $0.5^{\circ} \times 0.5^{\circ}$ spatial resolution by a statistical method in ISI-MIP (Hempel et al. 2013). This bias correction ensures the long-term statistics of the GCM outputs are consistent with the Water and Global Change (WATCH) during 1960-1999 (Weedon et al. 2011; Warszawski et al. 2014). Forty simulations (i.e., 5 GCMs $\times 8$ HMs) of daily discharge of 1971-2005 under historical scenario and of 2006-2100 under representative concentration pathway $2.6(\mathrm{RCP} 2.6)$ and RCP8.5 scenarios were used in this study.

\subsection{ENSO phases and NCAR-NCEP reanalysis data}


(CPC) over 1951-persent is used as El Niño-Southern Oscillation (ENSO) values in this study. The SOI values $>1$ is defined as extreme positive ENSO phase, while the

ENSO values $<1$ indicate extreme negative ENSO phase (Fig. S2). The monthly values of wind field and specific humidity over 1948-present are provided by the

National Centers for Environmental Prediction (NCEP)-National Center for Atmospheric Research (NCAR).

\subsection{Soil moisture data} wetness across Australia. water-year time series (i.e., July-June in the next year). The definitions of magnitude, 
volume, duration, and frequency of floods obtained from POT are shown in Fig. S3. A threshold in POT is selected so that two events per year on average can be sampled from the daily records. The spatial patterns of thresholds in annual flood events are comparable with those of heavy precipitation events (Fig. S4). The independence of flood events is evaluated by (Lang et al., 1999):

$$
\left\{\begin{array}{l}
D>5+\log (A) \\
Q_{\min }<\frac{3}{4} \min \left(Q_{1}, Q_{2}\right)
\end{array}\right.
$$

Where $D$ denotes the waiting time between two flood peaks; $A$ denotes the drainage area in mile ${ }^{2}$; and $Q_{1}$ and $Q_{2}$ denote the magnitudes of the two flood peaks in $\mathrm{m}^{3} / \mathrm{s}$. The Mann-Kendall test is used to detect changes of multivariate properties in floods and heavy precipitation (Mann 1945; Kendall 1975).

\subsection{Impacts of ENSO on floods}

Changes in floods are linked to large-scale climate variability (Mallakpour and Villarini 2016; Gu et al., 2017). The large-scale climate variability is often represented by climate indices, such as ENSO, IOD, SAM, and IPO, which have been proven to have noticeable impacts on flood variability across Australia (e.g., Johnson et al., 2016; Liu et al., 2018a). We calculate the correlation between flood events and the climate index such as ENSO in this study. Each flood event obtained from POT sampling is described by magnitude, duration and volume. The month and year of the peak discharge of each flood event were used to match the month and year of monthly ENSO values, resulting in a same length of coincident ENSO data. The Spearman method is used to compute the correlations between flood events (i.e. magnitude, 
volume and duration) and the coincident ENSO values. Among the four climate indices, the ENSO index is significantly correlated with POT flood series at the

222 largest number of the stations (Fig. S5). Therefore, we investigate the impacts of ENSO by quantifying the difference in flood magnitude, volume, frequency, and duration between extreme positive and negative ENSO phases. Student $t$ test is used to test whether there is a significant difference at the 0.05 significance level. transport (IVT) to explain the relationship between flood events and ENSO. IVT (unit: $\mathrm{kg} / \mathrm{m} / \mathrm{s}$ ) is a quantity that describes the total amount of transported water vapor to a location, and is calculated by integrating specific humidity, zonal and meridional

230 winds across different atmospheric levels based on NCEP-NCAR reanalysis dataset

231 (Mallakpour and Villarini 2016; Nayak et al., 2016):

$\mathrm{IVT}=\sqrt{\left(\frac{1}{g} \int_{\text {surface }}^{300} q u d p\right)^{2}+\left(\frac{1}{g} \int_{\text {surface }}^{300} q \nu d p\right)^{2}}$

Where, $q, u$, and $v$ are specific humidity $(\mathrm{kg} / \mathrm{kg})$, and zonal and meridional wind components $(\mathrm{m} / \mathrm{s})$, respectively; $g$ is the acceleration due to gravity $\left(\mathrm{m} / \mathrm{s}^{2}\right)$ and $p$ is pressure.

\subsection{Normalized changes in projected floods}

The future changes in floods are evaluated by the normalized changes of ISI-MIP simulations under RCP2.6 and RCP8.5. The magnitude, volume, frequency and

239 duration of floods in each grid are estimated based on POT during 1971-2100. The averages of these values during 1976-2005 and 2070-2099 are defined as $Q_{20 \mathrm{C}}$ and 


$$
\Delta Q=\frac{Q_{21 C}-Q_{20 C}}{Q_{21 C}+Q_{20 C}}
$$

Where $\Delta Q$ ranges between -1 and $+1 . \Delta Q$ values greater (smaller) than 0 indicate increases (decreases) in flood properties in warmer future.

\section{Results}

\subsection{Changes in the observed flood properties}

Fig. 2 shows the spatial patterns of changes in flood properties across Australia.

Most of catchments show no changes in all flood properties except for duration, and the percentages of no changes are $82.8 \%$ for magnitude, $81.9 \%$ for volume, $79.1 \%$ for frequency, and $26.8 \%$ for duration. The catchments with increases in flood properties are mainly in northern Australia, especially for the duration in the equatorial and tropical areas (Fig. 1 and Fig. 2). Increases in heavy precipitation properties are also found in this region (Fig. 4). In contrast, decreases in flood properties are observed in the catchments mainly located in southern Australia (especially the temperate areas), while we do not observe decreases in any heavy precipitation properties in this region

(Fig. 4). The possible reasons behind this inconsistency in changes between floods and heavy precipitation in southern Australia are discussed in next paragraphs.

We further evaluate the temporal variability in regional averages of flood events

261 in the equatorial and tropical areas (northern Australia) and temperate areas (southern

262 Australia), respectively (Fig. 2). The diametric changes (i.e., all flood properties increase in northern Australia but decrease in southern Australia) are more evident. A 
stronger tendency towards increases in the flood volume and duration are apparent (+129 $\mathrm{m}^{3} /$ year for volume and +0.56 day/year for duration; both reach the 0.05 significance level) in northern Australia. We also observe the decreases in all flood properties (in particular frequency and duration with slopes of -0.02 event/year and -0.21 day/year, respectively; both reach the 0.05 significance level) in temperate areas. Significant decreases in flood magnitudes were also found by Ishak et al. (2013) and Ishak and Rahman (2015) in this region..

To explore the potential spatial similarities of the changes in flood properties, the patterns of increases or decreases in the magnitude, volume, frequency and volume of floods can be classified into three distinct groups: all flood properties show no (NC, no change), increasing ( $\mathrm{AI}$, all increasing), and decreasing ( $\mathrm{AD}$, all decreasing) changes (Fig. 3). The three groups are classed using a hierarchal agglomerative clustering approach (Tan et al., 2006; Olden et al., 2012) based on the four at-site Kendall tau values (Helsel and Hirsh 2002) which measure changes in the magnitude, volume, frequency and duration of flood events (Fig. S6). The Kendall tau values are calculated by the correlations between time and the flood properties, and negative ones indicate decreases in the flood properties and vice versa. The agglomerative coefficient which is used to measure the clustering structure is 0.9949 (the maximum is 1) in this clustering, indicating the grouping is reasonable.

There is an apparent lack of geographic cohesion within NC group which contains $35.1 \%$ of the catchments. These catchments in NC group scatter across Australia (Fig. 3a). The NC group shows a tendency toward decreases in all flood 
properties as shown by the negative medians of Kendall tau values, although very few of them are statistically significant. $19.7 \%$ of the catchments are classed into AI group and most of these catchments are in northern Australia. Except for the frequency of flood events, the Kendall tau values of the other flood properties of more than $50 \%$ of the catchments are greater than 0.15 (i.e., the 0.1 significance level) (Fig. 3b). The AD group has the largest number of catchments (i.e. 45.1\%) among the three groups and

292 exhibits the strongest geographic cohesion. The AD catchments almost only occur in southern Australia (Fig. 3c). Widespread decreases in magnitude, volume, frequency and duration of flood events in $\mathrm{AD}$ group are observed, as more than $50 \%$ of the catchments in this group have negative Kendall tau values smaller than -0.15 in all flood properties. The catchment-based and regional changes in each flood property are consistent with the results of cluster analyses based on multidimensional nature of northern Australia and southern Australia. are highly consistent (Figs. 2 and 4). Heavy precipitation increases significantly by $+0.05 \mathrm{~mm} /$ year for magnitude, $+5.19 \mathrm{~mm} /$ year for volume, +0.07 event/year for frequency, and +0.11 day/year for duration (Fig. 4). The climate variations like wet and dry spells characterized as averaged and maximum lengths are stable in time in most of basins in northern Australia, and this is also the case for their regional averages in this region (Fig. 5). These results imply that heavy precipitation events play a major role in flood generating processes in northern Australia. 
flooding in northern Australia, because the response of floods to heavy precipitation

depends on antecedent hydrologic conditions and wetness state of the catchment

(Sharma et al., 2018). 90-day and 180-day antecedent water storage (defined by the amounts of precipitation minus evapotranspiration) prior to the flood event are calculated to analyze changes in antecedent hydrologic conditions (Fig. 6a and 6b).

Both the 90-day and 180-day antecedent water storage show increases in the basins in northern Australia, indicating that a wetness antecedent condition exists ahead the flooding. The percentage of heavy precipitation events leading to flooding will be largely amplified, if the precipitation is conditioned on the catchment being wet increases is observed in both surface and root zone soil moisture in northern Australia, suggesting that basin hydrologic condition is also being wetting in this region. Clearly, to flooding in northern Australia. is the infiltration excess (Johnson et al., 2016). In this generating mechanism, flooding is likely to occur in the situation where the instantaneous precipitation intensity is remarkably higher than the soil hydraulic conductivity (Mirus and Loague, 2013). 
precipitation in a short period, and then trigger flooding in northern Australia. We can

conclude that the increases of flood events in northern Australia can be largely attributed to the increasing heavy precipitation conditioned antecedent catchment wetness and wetting soil moisture.

In southern Australia, the significant decreases in flood properties cannot be attributed to the slight increases in heavy precipitation (Figs. 2 and 4). For most of catchments in southern Australia, the dominant flood-generating mechanism is the saturation excess where soil moisture dependent precipitation excess plays a more important role in controlling flooding (Trancoso et al., 2016). A significantly decreasing trend is observed in both averaged length and maximum length of wet spell in southern Australia (Figs. 5c and 5d), suggesting that the climate becomes drying. The drying climate was lengthened and amplified in the hydrological drought. During the period of 1997-2009, southeastern Australia experienced a record-breaking drought known as "the Millennium drought" (1997-2009) (Yang et al., 2017). Comparing the period of "the Millennium drought" with pre-drought period, the average precipitation in southeastern Australia decreased by $13 \%$, which resulted in about $45 \%$ decline in streamflow (Van Dijk et al., 2013).

The drying climate is also confirmed by the obvious decreases in the 90 -day and 180-day antecedent water storage prior to the flood event in southern Australia (Figs. 6a and 6b). When the antecedent catchment wetness is declining, the percentage of heavy precipitation events leading to flooding will be substantially reduced (Ivancic and Shaw, 2015). Surface soil moisture drying also exists in southern Australia, and it 
is more prominent in root zone soil moisture (Figs. 6c and 6d). The drying soil moisture infiltrates a larger portion of runoff into the soil and then reduces flood magnitude, volume, and duration in southern Australia.

\subsection{Relation of spatial patterns in flood temporal variability to ENSO}

Although the diametric changes in floods between northern and southern Australia are detected out, these changes may be plausible and not secular due to the relative short record (i.e. only 37 years). For example, the magnitude of Australian floods in tropical areas indicates an obviously declining trend during 1975 to around 1990, while a significantly increasing phase is around 1990 to 1998 (Fig. 2a). Flood duration shows decrease during 1975-1990 and increase during 1990-2012 in northern Australia. The change shift in some flood properties may be associated with the large variability of floods. It can be seen in Fig. 2 that the changes in regional averages of floods are dominated by inter-annual and/or decadal variability. Here, our hypothesis is that the temporal variability in floods is related to the variability in the climate system which can be reflected by the large-scale climate index (i.e. ENSO in this study) (Ward et al., 2014; Liu et al., 2018a). The cross correlations between 0, 1, 2, 3, 4, 5, and 6 month lags between flood event and the preceding $n$ month ENSO value (where $n=0,1,2,3,4,5$, and 6) are conducted. How to match of flood event and monthly ENSO values can refer to Section 3.2. The fractions of significant correlations with lag-0 and lag-1 ENSO are maximum among these lags, i.e. $16.9 \%$ and $20.8 \%$ for magnitude, $19.4 \%$ and $22.7 \%$ for volume, and $23.3 \%$ and $22.1 \%$ for duration, respectively (Fig. 7). When the lag is more than 6 months, the fraction of 
significant correlation is down to a low percentage.

Therefore, we show the difference in the four flood properties between extreme positive and negative lag-0 and lag-6 ENSO phases (Fig. 8). Most of significant differences in the four flood properties between extreme positive and negative ENSO phases are positive, and their spatial patterns are almost consistent between lag- 0 and lag-6. The catchments with positive differences are mainly in northern Australia and east northern Australia, and this is the case particularly for duration and frequency. Previous studies have detected tight relations between ENSO and precipitation extremes in the two areas of northern Australia where consistent increases in both floods and heavy precipitation are also observed (Fig. 2). In southern Australia (especially its southeast part), there is little evidence to suggest strong relations between ENSO values and flood properties in most catchments. The inconsistent changes between heavy precipitation and floods in southern Australia (Fig. 2) imply a weak correlation between ENSO and floods in this region.

The consistent changes of floods in northern Australia show geographic cohesion, especially for duration (Figs. 2 and 3), which could be partly demonstrated by the consistent positive relations between floods and ENSO in this region. The composite IVT anomaly and wind anomaly during the extreme ENSO positive phase are used to explain the physical mechanisms responsible for the relationships of flood properties with ENSO (Fig. 9). During the extreme ENSO positive phrase, the positive vapor transport anomalies over the equatorial and tropical Australia are observed, suggesting strengthened moisture transport in these regions. On the other hand, the negative 
vapor transport anomalies in the temperate areas indicate weakened moisture transport.

The spatial patterns of vapor transport anomalies composited in ENSO positive phrase

398 are highly consistent with the geographic cohesion of flood changes (i.e. diametric

399 changes in floods between northern and southern Australia, Figs. 2 and 3). Here, we

400 must note that this consensus in spatial patterns can not fully explain the geographic

401 cohesion due to around $80 \%$ of catchments show no differences during the extreme

402 positive and negative ENSO phases (Fig. 8). Nevertheless, the diametric changes in

403 floods between northern and southern Australia related to inter-annual variability are

404 partly linked to the effects of ENSO.

\subsection{Projected changes of floods in a multi-model framework}

We detected discrepancies of changes in observed floods between northern and southern Australia under climate change. The next question to address is then: would the diametric changes continue in a warmer future? The 40 combinations of HMs and GCMs are employed to simulate floods over the $21^{\text {st }}$ century under RCP2.6 and RCP8.5. Precipitation, temperature, and other weather variables from GCMs under historical and the two RCP scenarios are employed to drive the HMs. To simulate the impacts of different global warming levels on floods, human activities such as population, GDP, irrigation, and land use/land cover are not considered in the simulations.

The Quantile-quantile plots of simulated and observed flood peaks in the four selected catchments show that the multi-model ensemble means of the 40 combinations of HMs and GCMs performs reasonably to represent flood conditions 

models agree the decreases in all flood properties in southern Australia (Figs. 11 and 12) where the decreasing flood risk was also projected by previous studies

421 (Winsemius et al., 2016; Asadieh and Krakauer 2017). The decreases are more intense during 2070-2099 under RCP8.5 (representative of a $4^{\circ} \mathrm{C}$ warmer world compared to the pre-industrial era) than under $\mathrm{RCP} 2.6$ (a $2^{\circ} \mathrm{C}$ warmer world). We also observe increases in magnitude and volume of flood events in central-northern Australia but with high uncertainties. The regional averages in flood magnitude and volume anomalies of multimodel ensemble means during 1970-2099 relative to 1976-2005 show increases in northern Australia but decreases in southern Australia under evaluated (Fig. S7). It is more evidence that the flood magnitudes are projected to increase in northern Australia (more than $60 \%$ of models agree the increases more return levels (e.g. 50-year) and warmer climates (e.g. RCP8.5). Australia, i.e. increases in northern Australia and decreases in southern Australia. Though the changes during 1975-2012 are not evidently visible in terms of the 
number of unregulated catchments with 0.05 significance level, the changes of

441 regional averages of flood properties are mostly significant and prominent. Increases

442 of flood events in northern Australia are attributable to the increasing heavy

443 precipitation conditioned antecedent catchment wetness and wetting soil moisture,

444 while the drying catchment wetness state and climate lead to the decreases of flooding

445 in southern Australia. It should be noted that these changes in floods may be plausible

446 and not secular due to the relative short record, and could be dominated by

447 inter-annual and/or decadal variability.

448 We future analyze the relations between the temporal variability in floods and the

449 variability in the climate system (i.e. ENSO in this study). Positive differences in

450 flooding between extreme positive and negative ENSO phases are mainly in northern

451 Australia which shows consistent increases in both floods and heavy precipitation,

452 while there is little evidence to suggest strong relations between ENSO values and

453 flood properties in most catchments of southern Australia. The geographical

454 consistency between the changing patterns of flood properties and spatial patterns of

455 vapor transport anomalies could partly explain the geographic cohesion of flood

456 changes (i.e. diametric changes in floods between northern and southern Australia).

457 Finally, we explore whether the diametric changes in floods would be continue in

458 the future. The observed decreases in floods in southern Australia are projected to

459 continue with high model agreement under a warmer climate, while only magnitude

460 and volume of floods in northern Australia are projected to increase but with low

461 model agreement. Compared to RCP2.6, under RCP8.5 (representative of a $4^{\circ} \mathrm{C}$ 
warmer world compared to the pre-industrial era), this feature (decreases in southern Australia and increases in flood magnitude and volume in northern Australia) would be more pronounced. We also noted that the diametric changes of flood magnitude between northern and southern Australia are projected to be more evident in extreme (i.e. 50-year) floods than small (i.e. 5- and 20-year) floods. Our findings are critical to improve the understanding of the changing nature of flooding across Australia and can be assessed and communicated from a practical standpoint in terms of the local threat to people and assets.

It should be also noted the large uncertainties in simulated flood events in individual models (Fig. 10). Hydrologic regimes are usually better monitored in larger rivers in terms of drainage basin area and flood magnitude. The flood magnitude in larger rivers is greater enough relative to mitigate the impacts of the systematical biases and errors in HMs and GCMs (Li et al., 2016). In ISI-MIP, HMs are large-scale land surface models driven by the outputs of GCMs with coarse spatial resolution, which leads to higher uncertainties in small basins with relatively low river discharge in southern Australia (Fig. S1). Additionally, Teng et al. (2012) employed five rainfall-runoff models and 15 GCMs to simulate the runoff in southeast Australia, and pointed out that the uncertainty sourced from GCMs is much larger than the uncertainty in the rainfall-runoff models.

Natural variability, response uncertainty, and scenario uncertainty are the three sources of uncertainty in GCMs projecting climate change in the future (Hawkins and Sutton, 2009; Woldemeskel et al., 2016). Although the total uncertainty of CMIP5 
precipitation is visibly reduced due to a number of advances relative to CMIP3, the precipitation uncertainty is found to be larger in regions where heavy precipitation exists (Woldemeskel et al., 2016). The CMIP5 GCM outputs are bias corrected in ISI-MIP. Although the bias correction may add extra uncertainty to the projections, it can substantially improve the representation of precipitation properties (Nguyen et al., 2017). Additionally, low-frequency variability in GCM simulations is better represented after bias correction (Rocheta et al., 2014 and 2017), and this improvement in low-frequency variability is important for most hydrological studies where the eff ect of low-frequency variability is of considerable importance (Nguyen et al., 2017).

Another major limitation of this study is that the changes in vegetation due to changing climate and hydrologic conditions are not taken into consideration in the HMs. Variations in vegetation distribution also have consider impacts on streamflow (Liu et al., 2018b, 2019), especially for the flood generating processes in Australian temperate areas (Zhang et al., 2011).

Acknowledgments: This work is financially supported by the Strategic Priority Research Program Grant of the Chinese Academy of Sciences (Grant No. XDA19070402), the National Key Research and Development Program of China (Grant Nos. 2019YFA0606900 and 2018YFA0605603), the National Natural Science Foundation of China (Grants Nos. U1911205, 41901041 and 41771536), the Fund for Creative Research Groups of National Natural Science Foundation of China (Grant 

China (Grant No. 51425903), and the General Research Fund from the Research

508 Grants Council of the Hong Kong Special Administration Region, China (Grant No. HKBU12303517). We acknowledge the World Climate Research Programme's Working Group on Coupled Modelling, which is responsible for CMIP. We thank the

511 ISI-MIP coordination team for their efforts in producing, coordinating, and making

512 the model outputs publically available. Many thanks are given to NASA/GSFC for 513 producing and making available the GLDAS soil moisture data. The observed 514 streamflow data used are available at 515 https://publications.csiro.au/rpr/pub?pid=csiro:EP113194 and 516 http://www.bom.gov.au/water/hrs/index.shtml. The outputs of ISI-MIP are available at 517 https://esgf-index1.ceda.ac.uk/projects/esgf-ceda/. Monthly soil moisture data from 518 GLDAS are obtained at https://disc.sci.gsfc.nasa.gov/datasets?keywords=GLDAS. 519 The climate indices data are available from the Earth System Research Laboratory at 520 http://www.esrl.noaa.gov/psd/data/climateindices/list/, and the NCEP-NCAR reanalysis data are available at https://www.esrl.noaa.gov/psd/data/gridded/data.ncep.reanalysis.html. Our cordial

523 gratitude should be extended to the editor, Prof. Dr. Emmanouil Anagnostou, and 524 anonymous reviewers for their professional and pertinent comments and revision 525 suggestions, which are greatly helpful for further quality improvement of this current manuscript. 


\section{References}

Alfieri, L., Burek, P., Feyen, L., Forzieri, G., 2015. Global warming increases the frequency of river floods in Europe. Hydrology and Earth System Sciences 19, 2247-2260. https://doi.org/10.5194/hess-19-2247-2015.

Allen, M. R., Ingram, W. J., 2002. Constraints on future changes in climate and the hydrologic cycle. Nature 419, 224-232. https://doi.org/10.1038/nature01092.

Archfield, S. A., Hirsch, R. M., Viglione, A., Blöschl, G., 2016. Fragmented patterns of flood change across the United States. Geophysical Research Letters 43, 10232-10239. https://doi.org/10.1002/2016GL070590

Asadieh, B., Krakauer, N. Y., 2017. Global change in streamflow extremes under climate change over the 21st century. Hydrology and Earth System Sciences 21, 5863-5874. https://doi.org/10.5194/hess-21-5863-2017

Berghuijs, W. R., Woods, R. A., Hutton, C. J., Sivapalan, M., 2016. Dominant flood generating mechanisms across the United States. Geophysical Research Letters 43, 4382-4390. https://doi.org/10.1002/2016GL068070

Berghuijs, W. R., Aalbers, E. E., Larsen, J. R., Trancoso, R., Woods, R. A., 2017. Recent changes in extreme floods across multiple continents. Environmental Research Letters 12, 114035. https://doi.org/10.1088/1748-9326/aa8847

Bierkens, M. F. P., and L. P. H. van Beek, 2009. Seasonal predictability of European discharge: NAO and hydrological response time. Journal of Hydrometeorology 10, 953-968. https://doi.org/10.1175/2009JHM1034.1

Blöschl, G., Hall, J., Parajka, J., 2017. Changing climate shifts timing of European 
Box, P., Thomalla, F., van den Honert, R., 2013. Flood Risk in Australia: Whose Responsibility Is It, Anyway? Water 5, 1580-1597. https://doi.org/10.3390/w5041580

554

555

Bureau of Meteorology. Floods. Bureau of Meteorology, 2009. [updated 2009; cited 23 Mar 2009.] Available from

URL:

$$
\text { http://www.bom.gov.au/climate/c20thc/flood.shtml }
$$

Callaghan, J., Power, S. B., 2014. Major coastal flooding in southeastern Australia 1860-2012, associated deaths and weather systems. Australian Meteorological and Oceanographic Journal 64, 183-213. https://doi.org/10.22499/2.6403.002

Chen, Y., Yang, K., Qin, J., Zhao, L., Tang, W., \& Han, M., 2013. Evaluation of AMSR - E retrievals and GLDAS simulations against observations of a soil moisture network on the central Tibetan plateau. Journal of Geophysical Research: Atmospheres 118, 4466-4475. https://doi.org/10.1002/jgrd.50301

Cheng, S., Huang, J., 2016. Enhanced soil moisture drying in transitional regions under a warming climate. Journal of Geophysical Research 121, 2542-2555. https://doi.org/10.1002/2015JD024559

Eichinger, W. E., Parlange, M. B., Stricker, H., 1996. On the Concept of Equilibrium Evaporation and the Value of the Priestley - Taylor Coefficient. Water Resources Research 32, 161-164. https://doi.org/10.1029/95WR02920.

Forootan, E., Khandu, Awange, J. L., Schumacher, M., Anyah, R. O., van Dijk, A. I. J. M., Kusche, J., 2016. Quantifying the impacts of ENSO and IOD on rain gauge 
and remotely sensed precipitation products over Australia. Remote Sensing of Environment 172, 50-66. https://doi.org/10.1016/j.rse.2015.10.027

Frieler, K., Lange, S., Piontek, F., et al., 2017. Assessing the impacts of $1.5{ }^{\circ} \mathrm{C}$ global warming - simulation protocol of the Inter-Sectoral Impact Model Intercomparison Project (ISIMIP2b). Geoscientific Model Development, 10, 4321-4345. https://doi.org/10.5194/gmd-10-4321-2017

Gu, X., Zhang, Q., Singh, V. P., Shi, P., 2017. Hydrological response to large-scale climate variability across the Pearl River basin, China: Spatiotemporal patterns and sensitivity. Global and Planetary Change 149, 1-13. http://dx.doi.org/10.1016/j.gloplacha.2016.12.016

Gu, X., Li, J., Chen, Y. D., Kong, D., Liu, J., 2019a. Consistency and discrepancy of global surface soil moisture changes from multiple model-based datasets against satellite observations. Journal of Geophysical Research http://dx.doi.org/10.1029/2018JD029304.

Gu, X., Zhang, Q., Li, J., Singh, V. P., Liu, J., Sun, P., \& Cheng, C., 2019b. Attribution of global soil moisture drying to human activities: A quantitative viewpoint. Geophysical Research $\quad$ Letters 2573-2582. https://doi.org/10.1029/2018GL080768

Gu, X., Zhang, Q., Li, J., Singh, V. P., Liu, J., Sun, P., et al., 2019c. Intensification and expansion of soil moisture drying in warm season over Eurasia under global warming. Journal of Geophysical Research: Atmospheres 124, 3765-3782. https://doi.org/10.1029/2018JD029776 
Guha-Sapir D, Below R, Hoyois, P., 2015. EM-DAT: international disaster database. Université Catholique de Louvain, Brussels, Belgium.

Gosling, S. N., and N. W. Arnell, 2011. Simulating current global river runoff with a global hydrological model: Model revisions, validation, and sensitivity analysis. Hydrological Processes 25, 1129-1145. https://doi.org/10.1002/hyp.7727

Hagemann, S., and L. D. Gates, 2003. Improving a subgrid runoff parameterization scheme for climate models by the use of high resolution data derived from satellite observations. Climate Dynamics 21, 349-359. https://doi.org/10.1007/s00382-003-0349-X

Halgamuge, M. N., Nirmalathas, A., 2017. Analysis of large flood events: Based on flood data during 1985-2016 in Australia and India. International Journal of Disaster Risk Reduction 24, 1-11. http://dx.doi.org/10.1016/j.ijdrr.2017.05.011

Hanasaki, N., S. Kanae, T. Oki, K. Masuda, K. Motoya, N. Shirakawa, Y. Shen, and K. Tanaka, 2008. An integrated model for the assessment of global water resources-Part 1: Model description and input meteorological forcing. Hydrology and Earth System Sciences 12, 1007-1025. https://doi.org/10.5194/hess-12-1007-2008

Hawkins, E., Sutton, R., 2009. The potential to narrow uncertainty in regional climate predictions. Bulletin of the American Meteorological Society 90, 1095-1108. https://doi.org/10.1175/2009BAMS2607.1.

Helsel, D. R., and R. M. Hirsch, 2002. Statistical Methods in Water Resources, Techniques of Water-Resources Investigations Book 4, Chap. A3., U.S. 
617

Hempel, S., K. Frieler, L. Warszawski, J. Schewe, and Piontek, F., 2013. A trend-preserving bias correction-The ISI-MIP approach. Earth System Dynamics 4, 219-236. https://doi.org/10.5194/esd-4-219-2013

Hirabayashi, Y., Mahendran, R., Koirala, S., Konoshima, L., Yamazaki, D., Watanabe, S., Kim, H., Kanae, S., 2013. Global flood risk under climate change. Nature Climate Change 3, 816-821. https://doi.org/10.1038/nclimate1911

Hodgkins, G., Whitfield, P. H., Burn, D. H., et al., 2017. Climate-driven variability in the occurrence of major floods across North America and Europe. Journal of Hydrology 552, 704-717. http://dx.doi.org/10.1016/j.jhydrol.2017.07.027

IPCC Climate Change 2013: The Physical Science Basis (eds Stocker, T. F., et al.) 1535 (Cambridge Univ. Press, 2013).

IPCC, 2014: Climate Change 2014: Synthesis Report. Contribution of Working Groups I, II and III to the Fifth Assessment Report of the Intergovernmental Panel on Climate Change [Core Writing Team, R.K. Pachauri and L.A. Meyer (eds.)]. IPCC, Geneva, Switzerland, $151 \mathrm{pp}$

Ivancic, T. J., \& Shaw, S. B., 2015. Examining why trends in very heavy precipitation should not be mistaken for trends in very high river discharge. Climatic Change 133(4), 681-693. https://doi.org/10.1007/s10584-015-1476-1

Ishak, E. H., Rahman, A., Westra, S., Sharma, A., Kuczera, G., 2013. Evaluating the non-stationarity of Australian annual maximum flood. Journal of Hydrology 494, 134-145. http://dx.doi.org/10.1016/j.jhydrol.2013.04.021 
638

639

640

641

642

643

644

645

646

647

648

649

650

651

652

653

654

655

656

657

658

659

Ishak, E., Rahman, A., 2015. Detection of changes in flood data in Victoria, Australia from 1975 to 2011. Hydrology Research 46, 763-776. http://dx.doi.org/10.2166/nh.2014.064

Johnson, F., White, C. J., van Dijk, A., et al., 2016. Natural hazards in Australia: floods. Climatic Change 139, 21-35. https://doi.org/10.1007/s10584-016-1689-y

Kendall, M. G., 1975. Rank Correlation Methods. Griffin, London, UK.

King, A. D., Alexander, L. V., Donat, M. G., 2013. Asymmetry in the response of eastern Australia extreme rainfall to low - frequency Pacific variability. Geophysical Research Letters 40, 2271-2277. https://doi.org/10.1002/grl.50427

Li, J., Chen, Y. D., Zhang, L., Zhang, Q., Chiew, F. H. S., 2016. Future changes in floods and water availability across China: linkage with changing climate and uncertainties. Journal of Hydrometeorology 17, 1295-1314. https://doi.org/10.1175/JHM-D-15-0074.1

Liang, X., D. P. Lettenmaier, E. F. Wood, and S. J. Burges, 1994. A simple hydrologically based model of land surface water and energy fluxes for general circulation models. Journal of Geophysical Research 99, 14415-14428. https://doi.org/10.1029/94JD00483

Lang, M., Ouardab, T. B. M. J., Bobee, B., 1999. Towards operational guidelines for over-threshold modeling. Journal of Hydrology 255, 103-117. https://doi.org/10.1016/S0022-1694(99)00167-5

Liu, J., Zhang, Y. Q., 2017. Multi-temporal clustering of continental floods and associated atmospheric circulations. Journal of Hydrology 555, 744-759. 
660

661

662

663

664

665

666

667

668

669

670

671

672

673

674

675

676

677

678

679

680

681

https://doi.org/10.1016/j.jhydrol.2017.10.072

Liu, J., Zhang, Y., Yang, Y., Gu, X., Xiao, M., 2018a. Investigating relationships between Australian flooding and large-scale climate indices and possible mechanism. Journal of Geophysical Research: Atmospheres 123, 8708-8723. https://doi.org/10.1029/2017JD028197

Liu, J., Zhang, Q., Song, C., Zhang, Y., Sun, P., Gu, X., 2018b. Hydrological effects of climate variability and vegetation dynamics on annual fluvial water balance in global large river basins. Hydrology and Earth System Sciences 22(7), 4047-4060. https://doi.org/10.5194/hess-22-4047-2018

Liu, J., Zhang, Q., Feng, S., Gu, X., Singh, V. P., Sun, P., 2019. Global Attribution of Runoff Variance Across Multiple Timescales. Journal of Geophysical Research: Atmospheres 124, 13962-13974. https://doi.org/10.1029/2019JD030539

Mallakpour, I., Villarini, G., 2016. Investigating the relationship between the frequency of flooding over the central United States and large-scale climate. $\begin{array}{llll}\text { Advances } & \text { in } \quad \text { Water } & \text { Resources } & 92,\end{array}$ http://dx.doi.org/10.1016/j.advwatres.2016.04.008

Mann, H. B., 1945. Nonparametric tests against trend. Econometrica 13, 245-259. http://dx.doi.org/10.2307/1907187

Merz, B., Vorogushyn, S., Uhlemann, S., Delgado, J., Hundecha, Y., 2012. HESS opinions "More efforts and scientific rigour are needed to attribute trends in flood time series". Hydrology and Earth System Sciences 16, 1379-1387. https://doi.org/10.5194/hess-16-1379-2012 
682

683

684

685

686

687

688

689

690

691

692

693

694

695

696

697

698

699

700

701

702

703

Min, S.-K., Cai, W., Whetton, P., 2013. Influence of climate variability on seasonal extremes over Australia. Journal of Geophysical Research-Atmospheres 118, 643-654. https://doi.org/10.1002/jgrd.50164

Mirus, B. B., Loague, K., 2013. How runoff begins (and ends): characterizing hydrologic response at the catchment scale. Water Resources Research 49, 2987-3006. https://doi.org/10.1002/wrcr.20218

Nayak, M. A., Villarini, G., Bradley, A., 2016. Atmospheric rivers and rainfall during NASA's Iowa flood studies (IFoodS) campaign. Journal of Hydrometeorology 17, 257-271. http://dx.doi.org/10.1175/JHM-D-14-0185.1

Nguyen, H., Mehrotra, R., Sharma, A., 2017. Can the variability in precipitation simulations across GCMs be reduced through sensible bias correction? Climate Dynamics, 49, 3257-3275. http://dx.doi.org/10.1007/s00382-016-3510-z

Nott, J., 2018. The influence of tropical cyclones on long-term riverine flooding; examples from tropical Australia. Quaternary Science Reviews 182, 155-162. https://doi.org/10.1016/j.quascirev.2017.11.035

Olden, J. D., M. J. Kennard, and B. J. Pusey, 2012. A framework for hydrologic classification with a review of methodologies and applications in ecohydrology. Ecohydrology 5(4), 503-518. https://doi.org/10.1002/eco.251

Pokhrel, Y., N. Hanasaki, S. Koirala, J. Cho, P. J.-F. Yeh, H. Kim, S. Kanae, and T. Oki, 2012. Incorporating anthropogenic water regulation modules into a land surface model. Journal of Hydrometeorology 13, 255-269. https://doi.org/10.1175/JHM-D-11-013.1 
Pui, A., Sharma, A., Santoso, A., Westra, S., 2012. Impact of the El Niñ o-Southern Oscillation, Indian Ocean Dipole, and Southern Annular Mode on daily to subdaily rainfall characteristics in east Australia. Monthly Weather Review 140, 1665-1682. https://doi.org/10.1175/MWR-D-11-00238.1

Rocheta, E., Sugiyanto, M., Johnson, F., Evans, J., Sharma, A., 2014. How well do general circulation models represent lowfrequency rainfall variability? Water Resources Research, 50, 2108-2123. https://doi.org/10.1002/2012WR013085

Rocheta, E., Evans, J. P., Sharma, A., 2017. Can bias correction of regional climate model lateral boundary conditions improve low-frequency rainfall variability? Journal of Climate, 30, 9785-9806. https://doi.org/10.1175/JCLI-D-16-0654.1

Sharma, A., Wasko, C., Lettenmaier, D. P., 2018. If Precipitation Extremes Are Increasing, Why Aren't Floods? Water Resources Research 54, 8545-8551. https://doi.org/10.1029/2018WR023749

Slater, L. J., Villarini, G., 2016. Recent trends in U.S. flood risk. Geophysical Research Letters 43. https://doi.org/10.1002/2016GL071199

Tan, P., M. Steinbach, and V. Kumar, 2006. Introduction to Data Mining, 769 pp., Pearson Addison Wesley, Boston, Mass.

Tang, Q., T. Oki, and S. Kanae, 2006. A distributed biosphere hydrological model (DBHM) for large river basin. Proceedings of Hydraulic Engineering 50, 37-42. https://doi.org/10.2208/prohe.50.37

Teng, J., Vaze, J., Chiew, F. H. S., Wang, B., Perraud, J.-M., 2012. Estimating the relative uncertainties sourced from GCMs and hydrological models in modeling 
climate change impact on runoff. Journal of Hydrometeorology 13, 122-139. https://doi.org/10.1175/JHM-D-11-058.1

Trancoso, R., Larsen, J. R., McAlpine, C., McVicar, T. R., Phinn, S., 2016. Linking the Budyko framework and the Dunne diagram. Journal of Hydrology 535, 581-597. https://doi.org/10.1016/j.jhydrol.2016.02.017

van Dijk, A. I. J. M., Beck, H. E., Crosbie, R. S., de Jeu, R. A. M., Liu, Y. Y., Podger, G. M., Timbal, B., Viney, N. R. 2013. The Millennium Drought in southeast Australia (2001-2009): Natural and human causes and implications for water resources, ecosystems, economy, and society. Water Resources Research 49, 1040-1057. https://doi.org/10.1002/wrcr.20123

Verdon, D. C., Wyatt, A. M., 2004. Multidecadal variability of rainfall and streamflow: Eastern Australia. Water Resources Research 40, W10201. https://doi.org/10.1029/2004WR003234

Villarini, G., Denniston, R. F., 2016. Contribution of tropical cyclones to extreme rainfall in Australia. International Journal of Climatology 36, 1019-1025. https://doi.org/10.1002/joc.4393

Vörösmarty, C. J., C. A. Federer, and A. L. Schloss, 1998. Potential evaporation functions compared on US watersheds: Possible implications for global-scale water balance and terrestrial ecosystem modeling. Journal of Hydrology 207, 147-169. https://doi.org/10.1016/S0022-1694(98)00109-7

Ward, P. J., Jongman, B., Kummu, M., Dettinger, M. D., Weiland, F. C. S., Winsemius, H. C., 2014. Strong influence of El Niño Southern Oscillation on flood risk 
around the world. Proceedings of the National Academy of Sciences of the United States of America 111, 15629-15664. https://doi.org/10.1073/pnas.1409822111

Warszawski, L., K. Frielet, V. Huber, F. Pointek, O. Serdeczny, and J. Schewe, 2014. The Inter-Sectoral Impact Model Intercomparison Project (ISI-MIP): Project framework. Proceedings of the National Academy of Sciences of the United States of America 111, 3228-3232. https://doi.org/10.1073/pnas.1312330110

Wasko, C., Pui, A., Sharma, A., Mehrotra, R., Jeremiah, E., 2015. Representing low-frequency variability in continuous rainfall simulations: A hierarchical random Bartlett Lewis continuous rainfall generation model. Water Resources Research 51, 9995-10007. https://doi.org/10.1002/2015WR017469

Weedon, G. P., et al., 2011. Creation of the WATCH forcing data and its use to assess global and regional reference crop evaporation over land during the twentieth century. Journal of Hydrometeorology 12, 823-848. https://doi.org/10.1175/2011JHM1369.1

Winsemius, H. C., Aerts, J. C. J. H., van Beek, L. P. H., et al., 2016. Global drivers of future river flood risk. Nature Climate Change 6, 381-385. https://doi.org/10.1038/NCLIMATE2893

Woldemeskel, F. M., Sharma, A., Sivakumar, B., Mehrotra, R., 2016. Quantification of precipitation and temperature uncertainties simulated by CMIP3 and CMIP5 models. Journal of Geophysical Research-Atmospheres, 121, 3-17. https://doi.org/10.1002/2015JD023719 
Yang, Y., McVicar, T. R., Donohue, R. J., Zhang, Y., Roderick, M. L., Chiew, F. H. S., Zhang, L., Zhang, J., 2017. Lags in hydrologic recovery following an extreme drought: Assessing the roles of climate and catchment characteristics. Water Resources Research 53, 4821-4837. https://doi.org/10.1002/2017WR020683.

Zhang, L., F. Zhao, Y. Chen, and R. N. M. Dixon, 2011. Estimating effects of plantation expansion and climate variability on streamflow for catchments in $\begin{array}{llll}\text { Australia. Water Resources } & \text { Research 47, W12539. }\end{array}$ https://doi.org/10.1029/2011WR010711

Zhang, Q., Gu, X., Singh, V. P., Xiao, M., 2014. Flood frequency analysis with consideration of hydrological alterations: Changing properties, causes and implications. Journal of Hydrology 519, 803-813. http://dx.doi.org/10.1016/j.jhydrol.2014.08.011

Zhang, Q., Gu, X., Singh, V.P., Shi, P., Luo, M., 2017. Timing of floods in southeastern China: seasonal properties and potential causes. Journal of Hydrology 552, 732-744.

Zhang, Y., Chiew, F. H., 2009. Relative merits of different methods for runoff predictions in ungauged catchments. Water Resources Research 45, W07412. https://doi.org/10.1029/2008WR007504

Zhang, Y. Q., Viney, N., Frost, A., Oke, A., Brooks, M., Chen, Y., and Campbell, N., 2013. Collation of Australian modeller's streamflow dataset for 780 unregulated Australian catchments. CSIRO: Water for a Healthy Country National Research Flagship, 115pp. 
792

793

794

795

796

797

798

799

800

801

802

Zhang, Y. Q., Zheng, H., Chiew, F. H. S., Arancibia, J. P., Zhou, X., 2016. Evaluating regional and global hydrological models against streamflow and evapotranspiration measurements. Journal of Hydrometeorology 17(3), 995-1010. http://119.78.100.206:8088/handle/311025/10244

Zhang, Y. Q., Post, D., 2019. How good are hydrological models for gap-filling streamflow data? Hydrology and Earth System Sciences 22, 4593-4604, https://doi.org/10.5194/hess-22-4593-2018

Zhou, Y., Zhang, Y., Vaze, J., Lane, P., Xu, S., 2013. Improving runoff estimates using remote sensing vegetation data for bushfire impacted catchments. Agriculture and Forest Meteorology

182, 332-341. http://dx.doi.org/10.1016/j.agrformet.2013.04.018 
X. Gu, Q. Zhang designed the study. X. Gu conducted the calculations. X. Gu, Q. Zhang wrote the manuscript with contributions from J. Li, J. Liu, C.-Y. Xu, P. Sun. All of the co-authors contributed to scientific interpretations and helped improve the manuscript. 


\section{Declaration of interests}

$\bigotimes$ The authors declare that they have no known competing financial interests or personal relationships that could have appeared to influence the work reported in this paper.

$\square$ The authors declare the following financial interests/personal relationships which may be considered as potential competing interests:

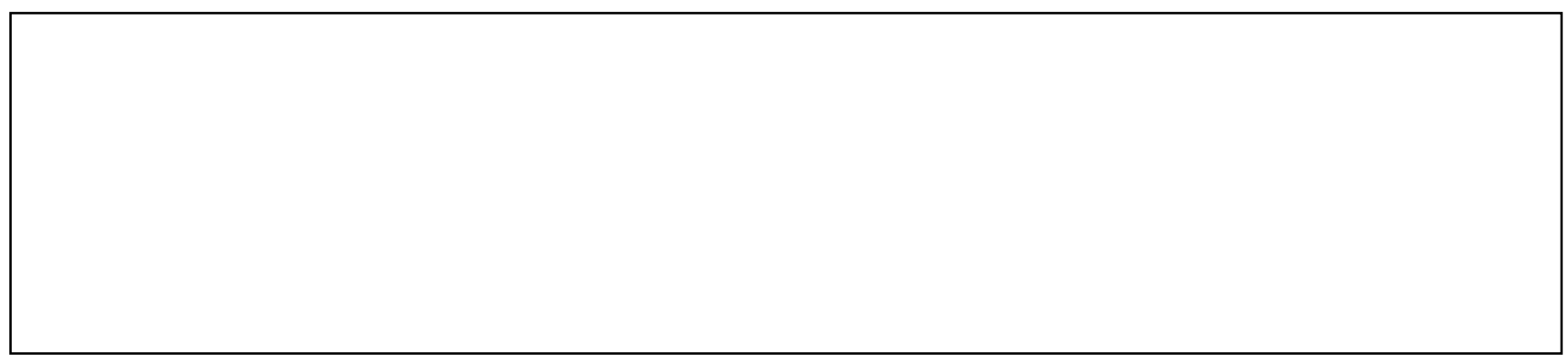


Dear editor,

This time I am writing to you for our revised version of HYDROL32297R. This paper was significantly revised and improved. The language was edited by Prof. Vijay P. Singh from Texas A\&M University, USA. Hopefully, the revised version could satisfy your requirements.

Please kindly let me know if any further questions.

All the best,

Qiang Zhang 


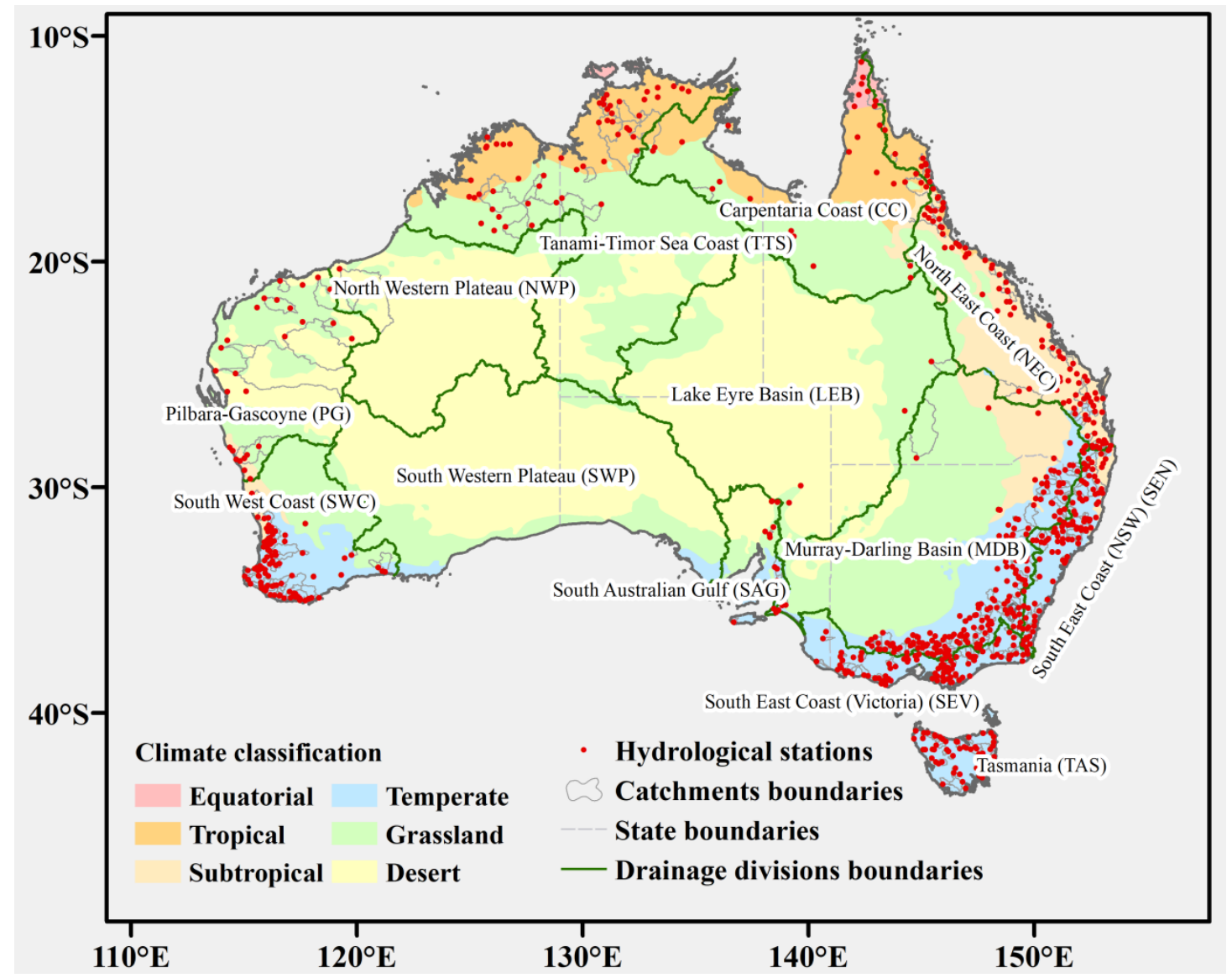

Fig. 1 Location of the 780 unregulated catchments, climate zones and major water basins in Australia. 


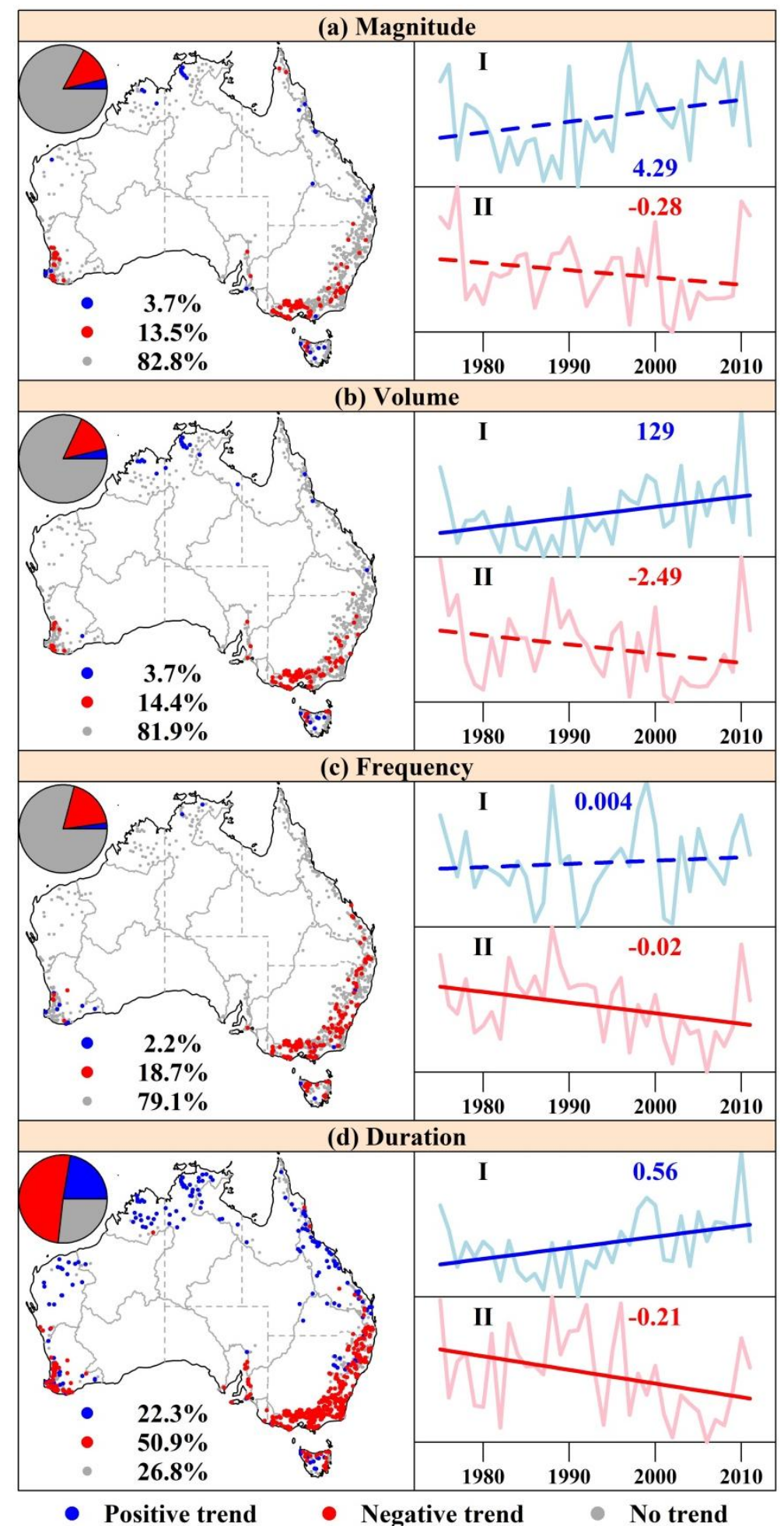

Fig. 2 Changes in magnitude, volume, frequency and duration of floods over Australia. The light blue (red) line with in each panel labelled by "I" ("II") indicates the changes in regional averages over the equatorial and tropical (temperate) areas (see Fig. 1). The colored straight lines are the trends of the corresponding regional averages, in which solid (dashed) lines indicate the trend at the 0.05 significance level. The blue (red) numbers are the slopes of the blue (red) straight lines, with unit $\mathrm{m}^{3} / \mathrm{s} /$ year for magnitude, $\mathrm{m}^{3} /$ year for volume, events/year for frequency, and day/year for duration. 


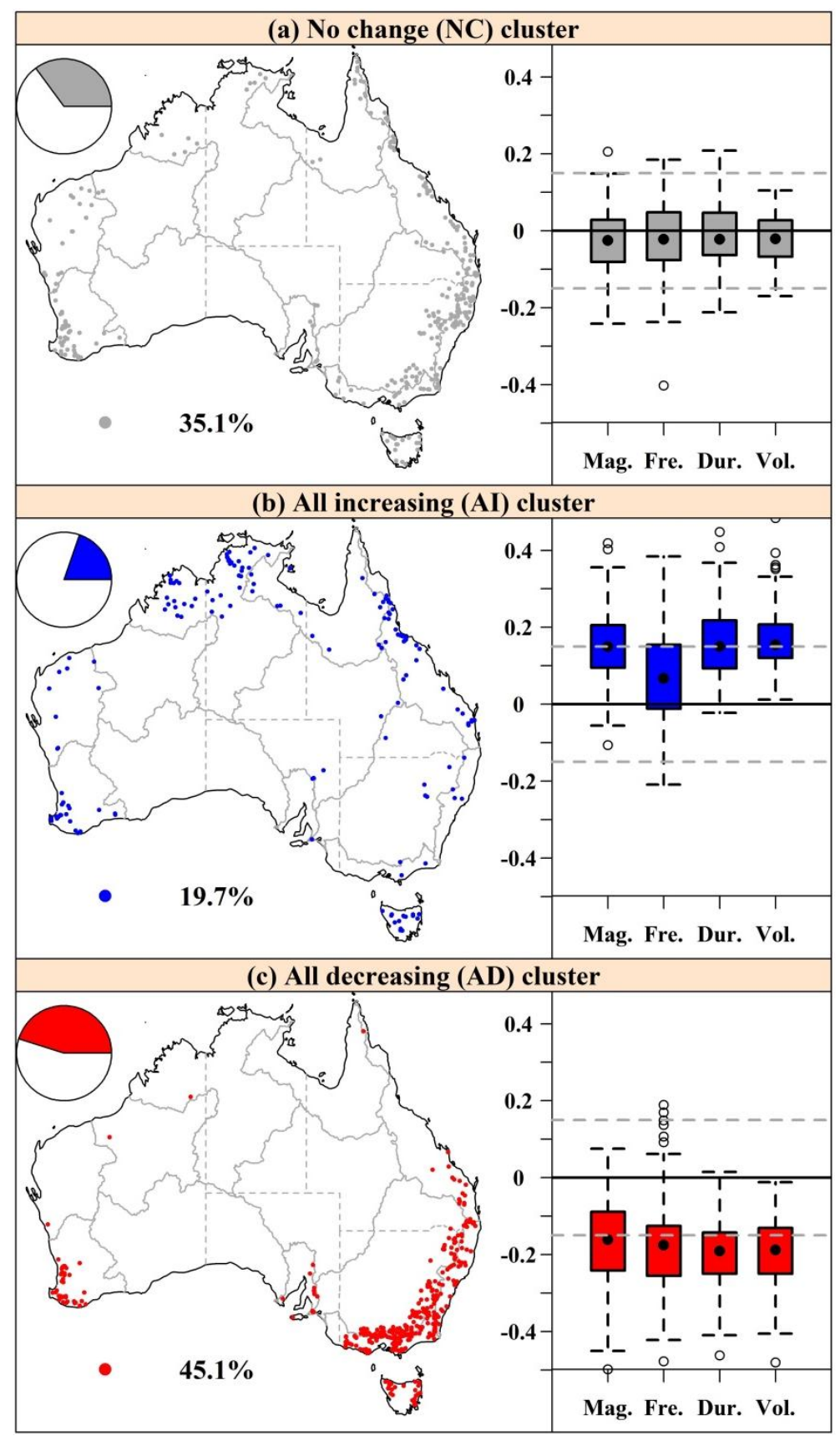

Fig. 3 Catchments clustered into groups experiencing similar changes in the magnitude (Mag.), frequency (Fre.), duration (Dur.), and volume (Vol.) during the period of 1975-2012. Catchments in (a) the no change (NC) group generally show no change in the flood properties, in (b) the all increasing (AI) group show increases across all flood properties, and in (c) all decreasing (AD) group show decreases across all flood properties. Box plots of the Kendall tau values - a measure of relation between time and the flood properties - for the catchments within each group is shown to the right of each map. A negative Kendall tau value indicates a decreasing trend, and a positive value indicates an increasing trend. Correlations above values of 0.15 and below values of 0.15 (shown in dashed gray lines) are significant at the 0.1 significance level. 


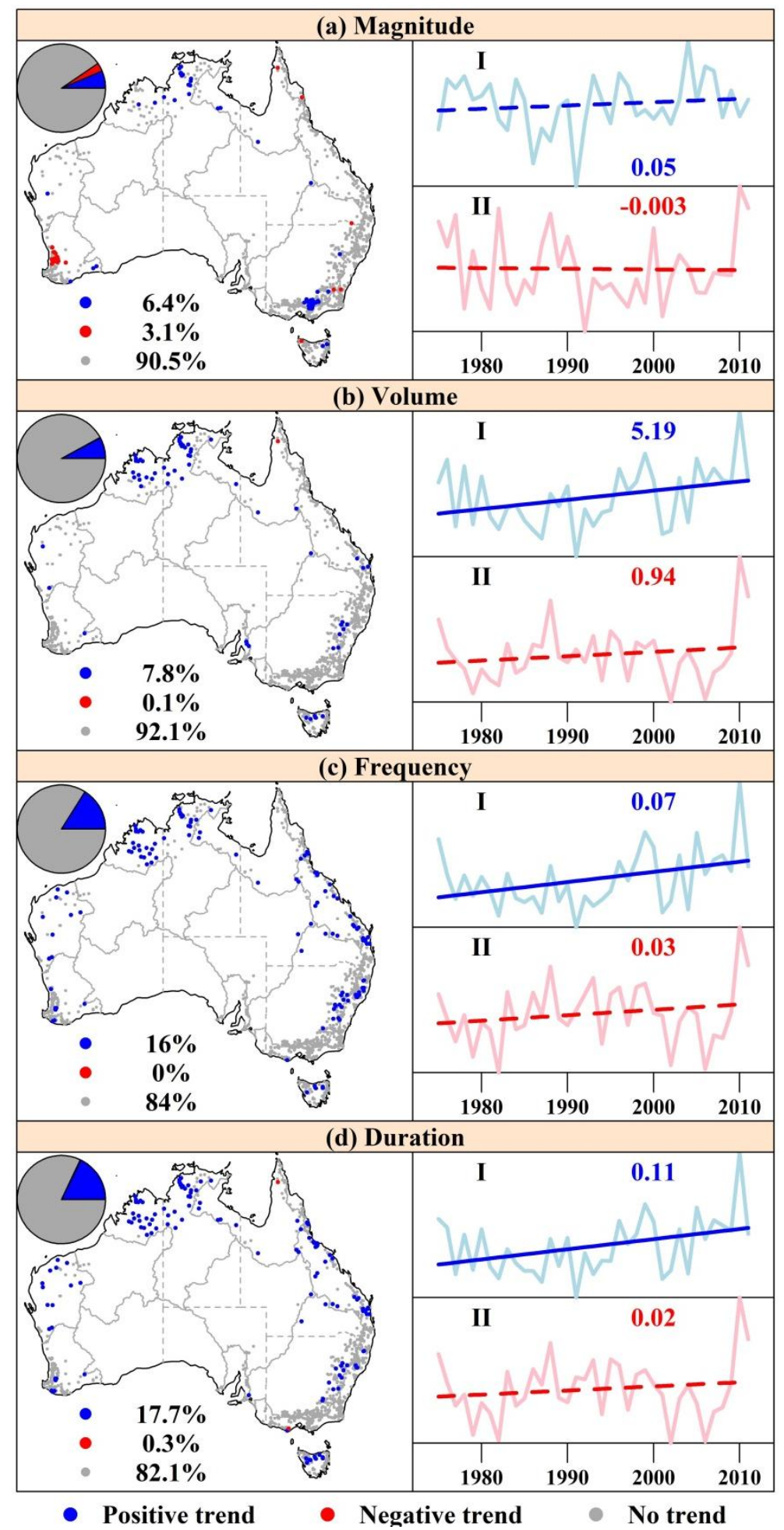

Fig. 4 Changes in magnitude, volume, frequency and duration of heavy precipitation events over Australia. The light blue (red) line in each panel labelled by "I" ("II") indicates the changes in regional averages over the equatorial and tropical (temperate) areas. The colored straight lines are the trends of the corresponding regional averages, in which solid (dashed) lines indicate the trend at the 0.05 significance level. The blue (red) numbers are the slopes of the blue (red) straight lines, with unit $\mathrm{mm} /$ day/year for magnitude, $\mathrm{mm} / \mathrm{year}$ for volume, events/year for frequency, and day/year for duration. 


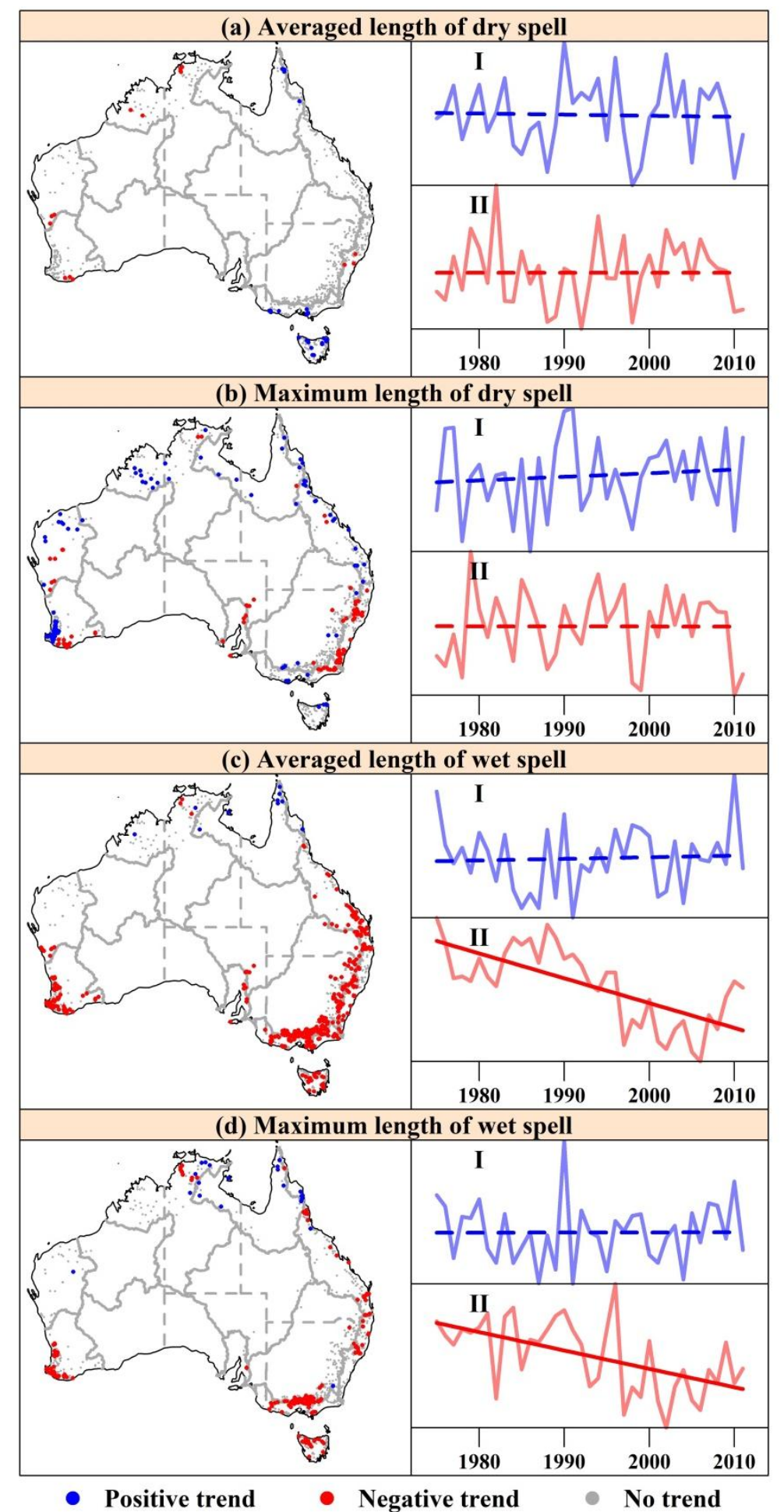

Fig. 5 Changes in (a) averaged length of dry spell, (b) maximum length of dry spell, (c) averaged length of wet spell, and (d) maximum length of wet spell over Australia. The light blue (red) line in each panel labelled by "I" ("II") indicates the changes in regional averages over the equatorial and tropical (temperate) areas. The colored straight lines are the trends of the corresponding regional averages, in which solid (dashed) lines indicate the trend at the 0.05 significance level. 


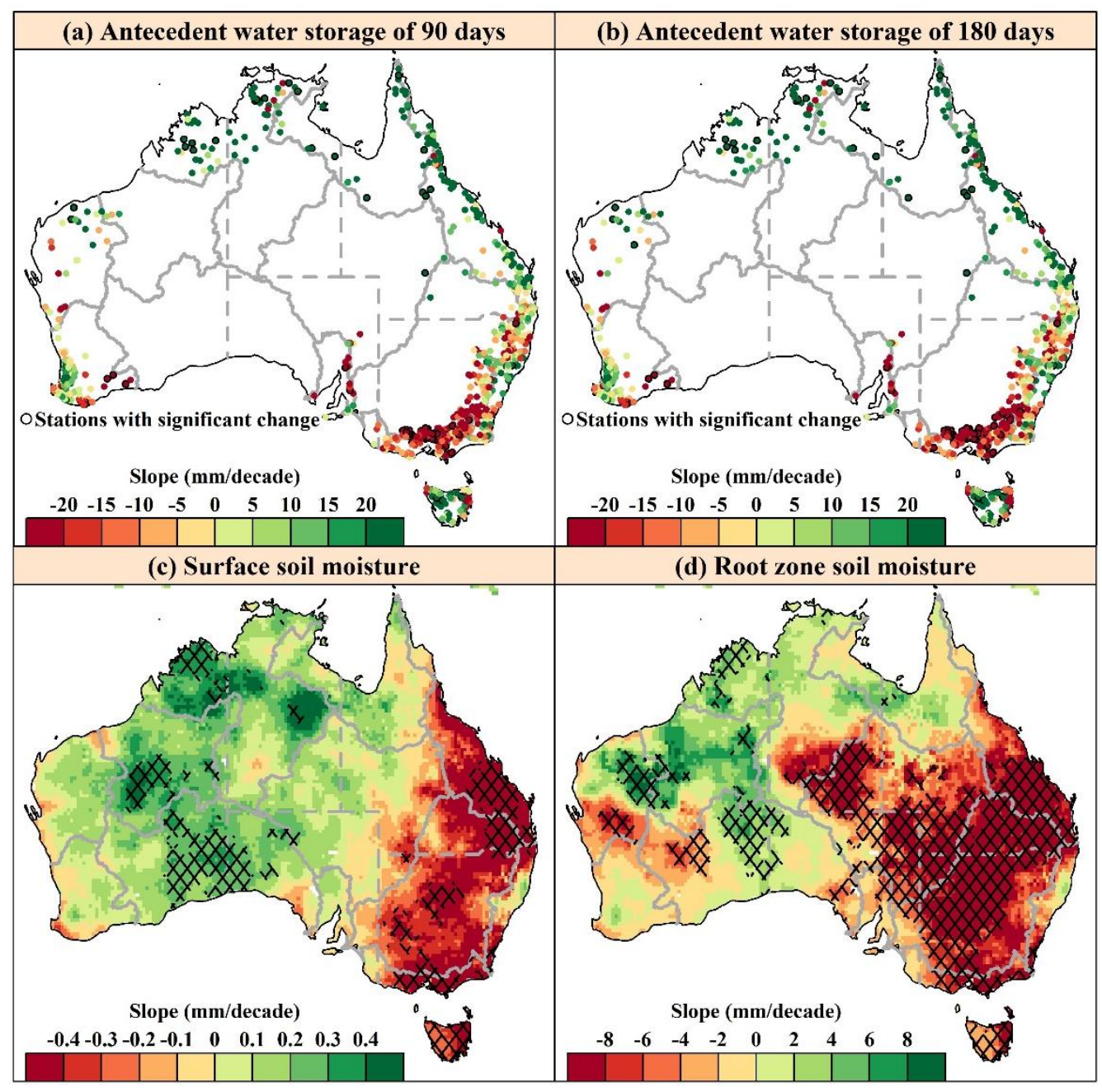

Fig. 6 Changes in (a) 90-days and (b) 180-days antecedent water storage before flood peaks, and (c) surface soil moisture $(0-0.1 \mathrm{~m})$ and (d) root zone soil moisture $(0-1 \mathrm{~m})$ over Australia. In (c) and (d), the areas with cross black lines indicate changes at the 0.05 significance level. 


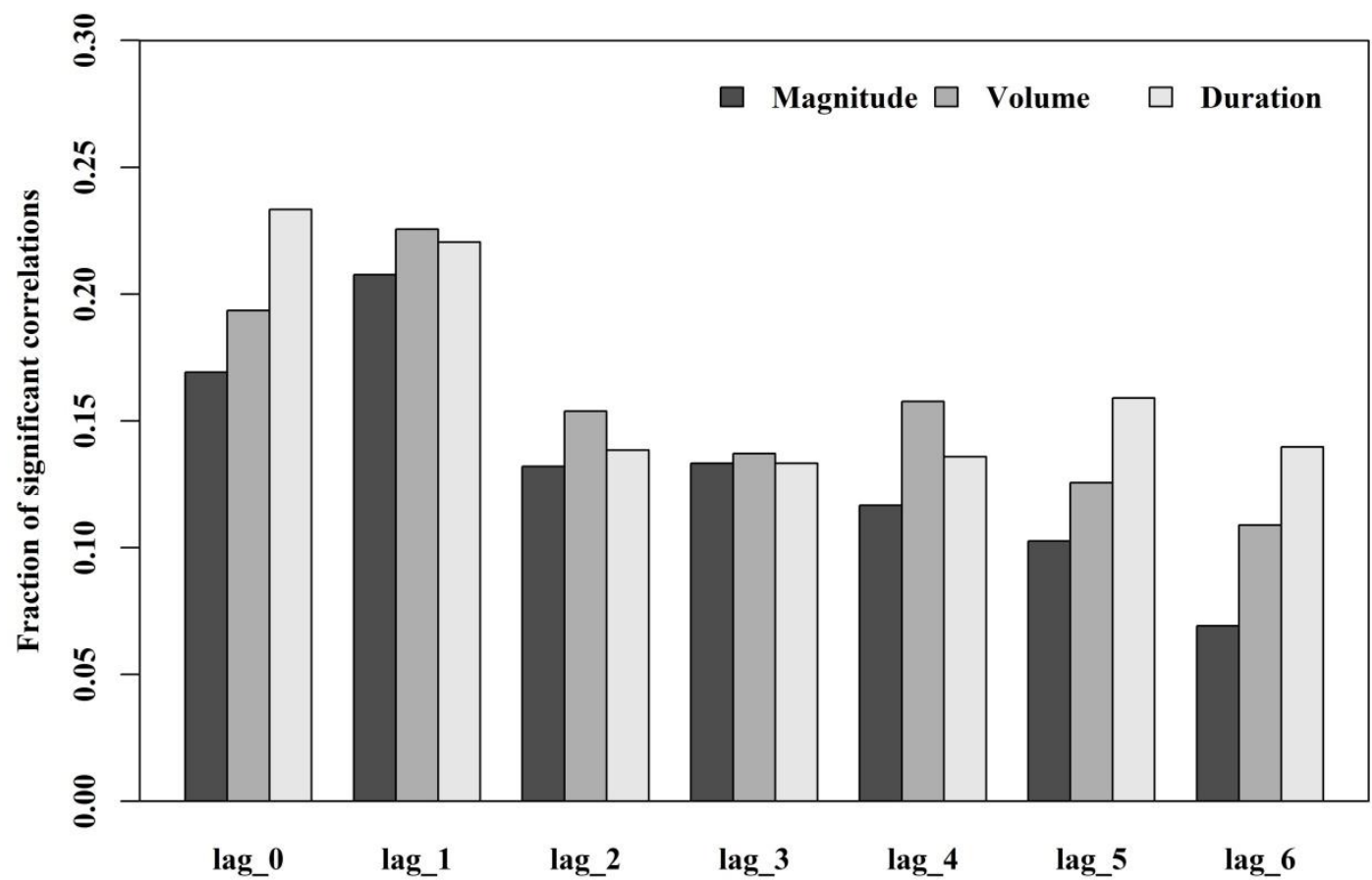

Fig. 7 Fractions of significant correlations with lag 0-6 of El Niño-Southern Oscillation (ENSO) with the magnitude, volume and duration of flood events. For the time series of magnitude, volume and duration of flood events, the month and year of each flood event occurrence defined the month and year that were matched to the month and year of ENSO time series; then coincident data of flood events and climate indices were used to estimate their correlations by Spearman method. The cross correlations between 1, 2, 3, 4, 5, and 6 month lags between the flood event and the preceding $n$ month ENSO value ( $n=1,2,3,4,5$, and 6 ) are also computed. The fractions (i.e. the values in $y$ axis) indicate the ratios of the number of catchments with significant correlations to total catchments (i.e. 780). 


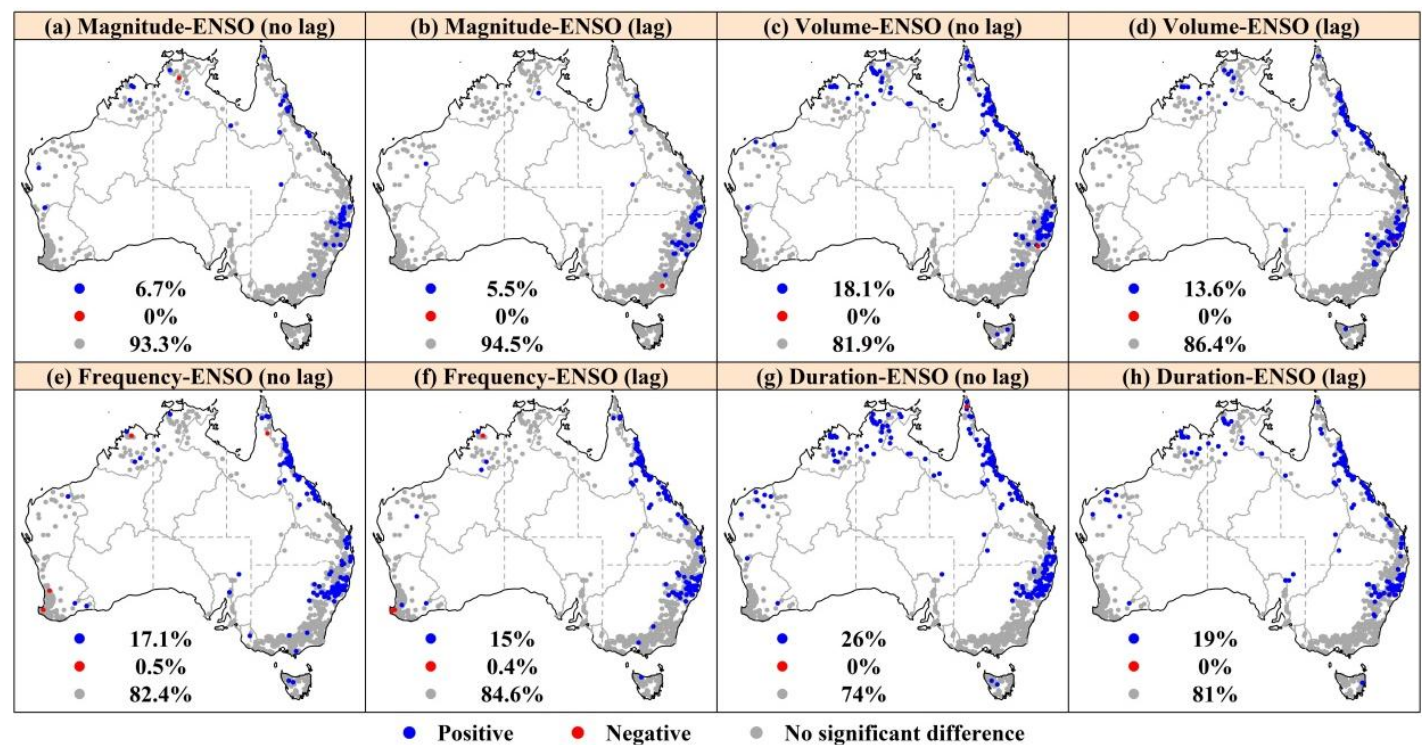

Fig. 8 Maps for the difference in flood magnitude, volume, frequency, and duration between extreme positive and negative ENSO phases. "no lag" and "lag" indicate ENSO values zero month and six months ahead of flood events, respectively. The extreme positive (negative) ENSO phase is defined as ENSO values more (less) than 1. Student $t$ test is used to test whether there is a difference at the 0.05 significance level in flood magnitude, volume, frequency, and duration between extreme positive and negative ENSO phases. Blue (red) dots indicate positive (negative) difference, suggesting that the flood magnitude, volume, frequency, and duration are significantly higher in extreme positive ENSO phase than in extreme negative ENSO phase. 


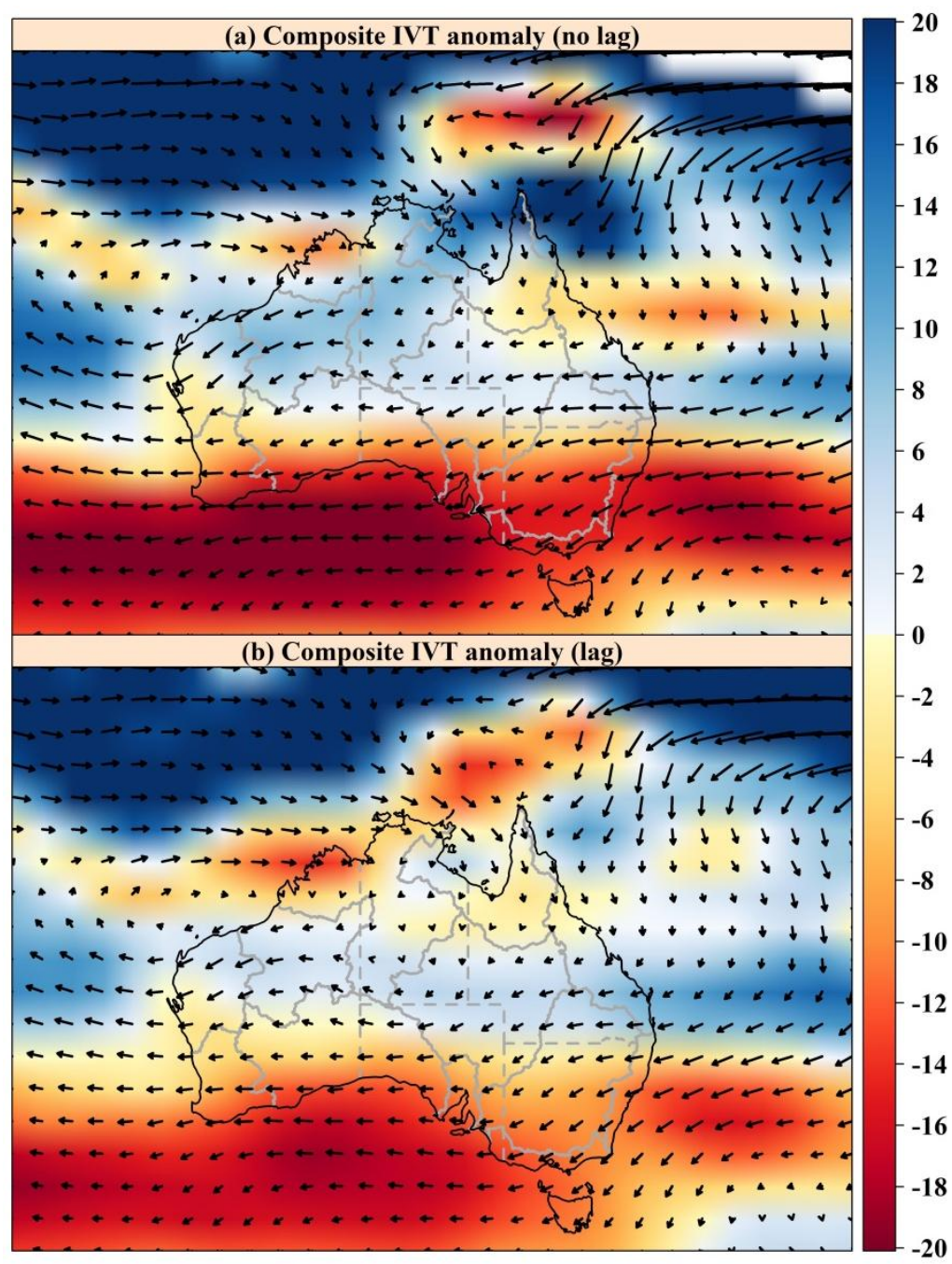

Fig. 9 Composite integrated vapor transport (IVT) anomaly in $\mathrm{kg} / \mathrm{m} / \mathrm{s}$ and wind field anomaly at $850 \mathrm{hPa}$ in $\mathrm{m} / \mathrm{s}$ during the extreme positive phase of ENSO. "no lag" and "lag" indicate ENSO values zero month and six months ahead of flood events, respectively. 

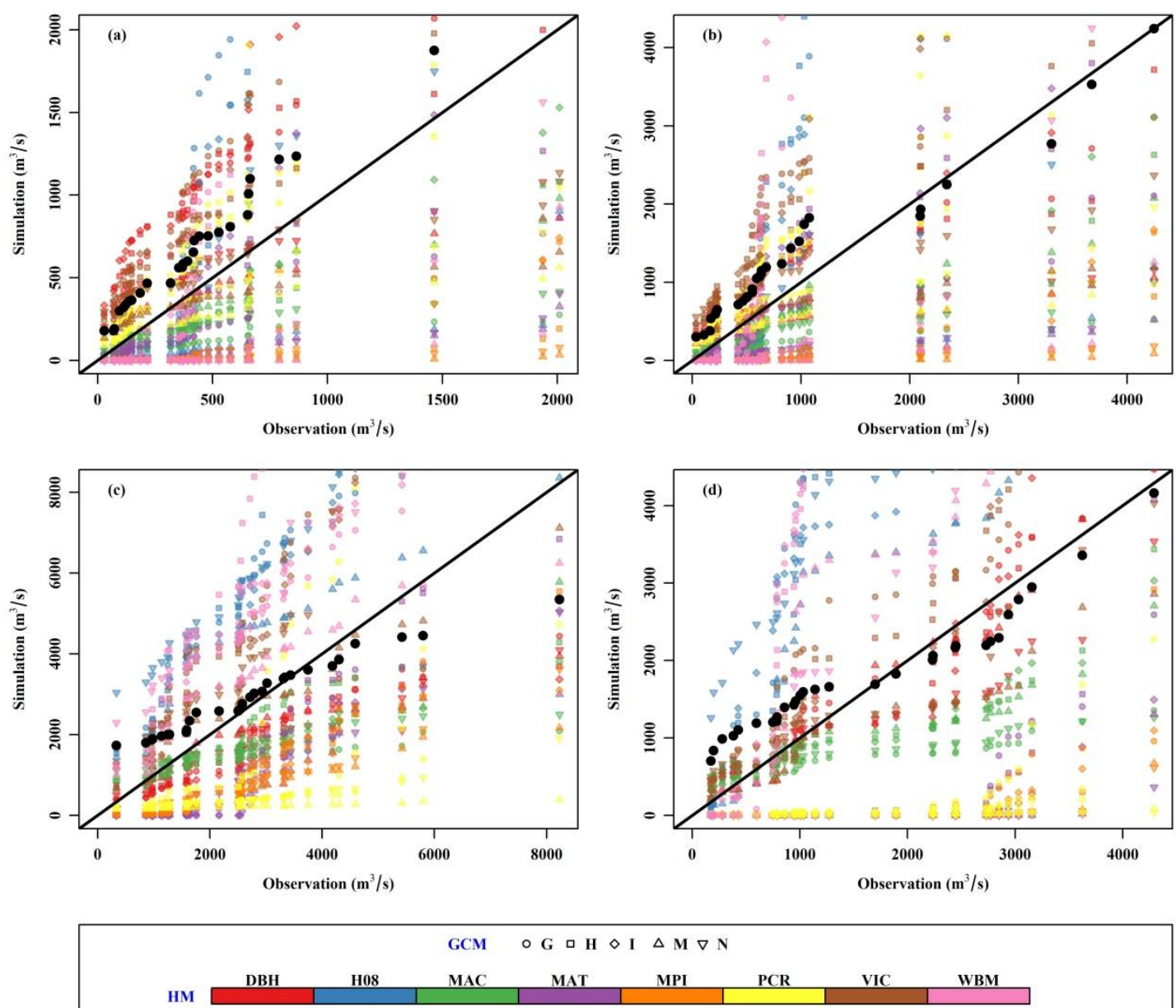

Fig. 10 Quantile-quantile plots of observed and simulated annual maximum daily discharge during the 1975-2005 period. The black dots indicate the multimodel ensemble mean of flood peaks in the 40 models. The selected four catchments (i.e. a-d) are located in four catchments of the ten with maximum drainage areas in the 780 catchments (see Fig. S1). 


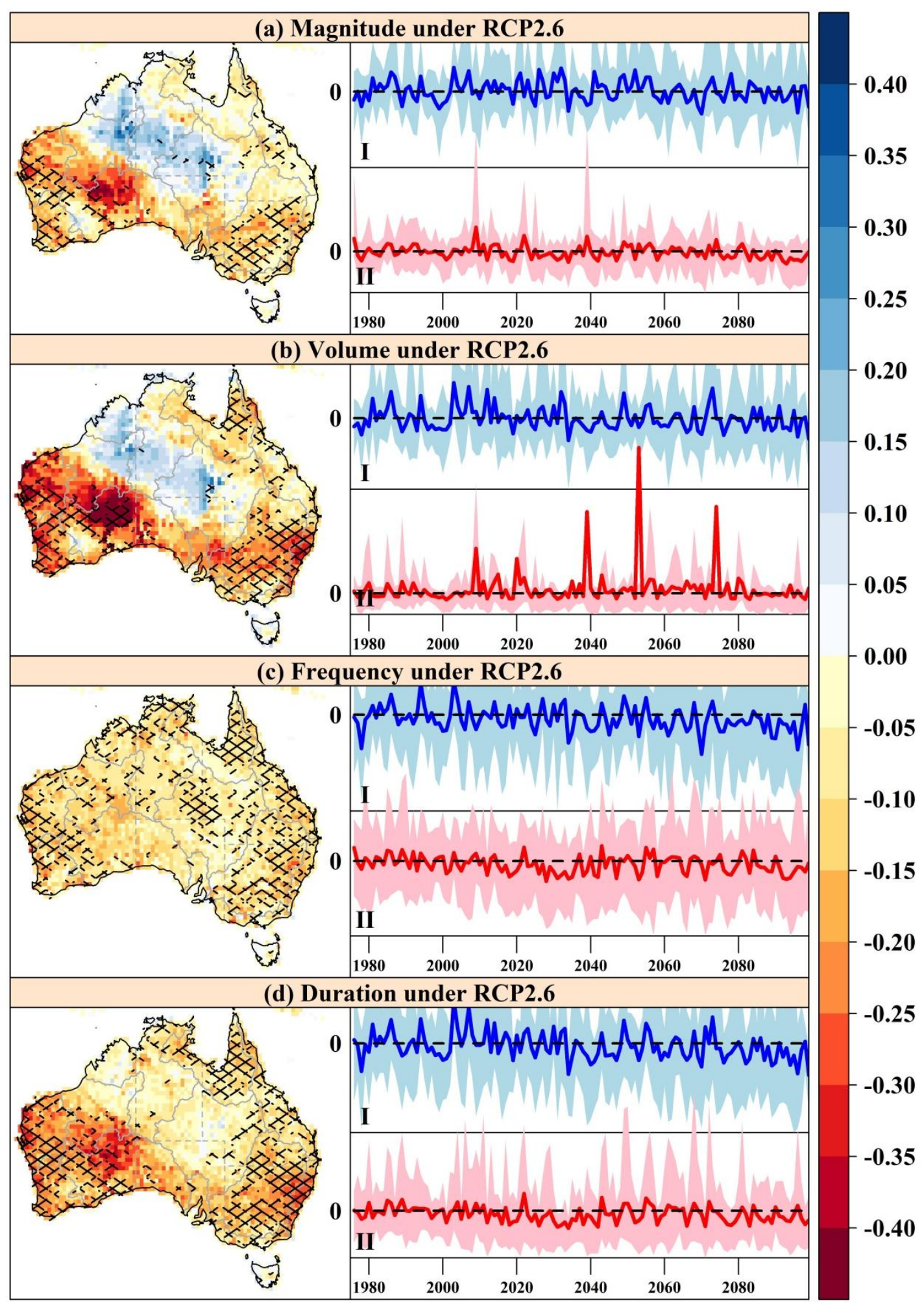

Fig. 11 Multimodel ensemble mean of normalized changes in flood properties across Australia over 2070-2099 under RCP2.6 relative to 1976-2005 under historical scenario (left panels), and the anomalies in multimodel ensemble mean of regional averages over the equatorial and tropical (I) and temperate (II) areas during 1976-2099 (right panels). In the left panels, the areas with black lines indicate more than $60 \%$ of the 40 models agree with the results of multimodel ensemble mean. In the right panels, the colored shadows are the 5-95\% ranges of the corresponding regional averages. 


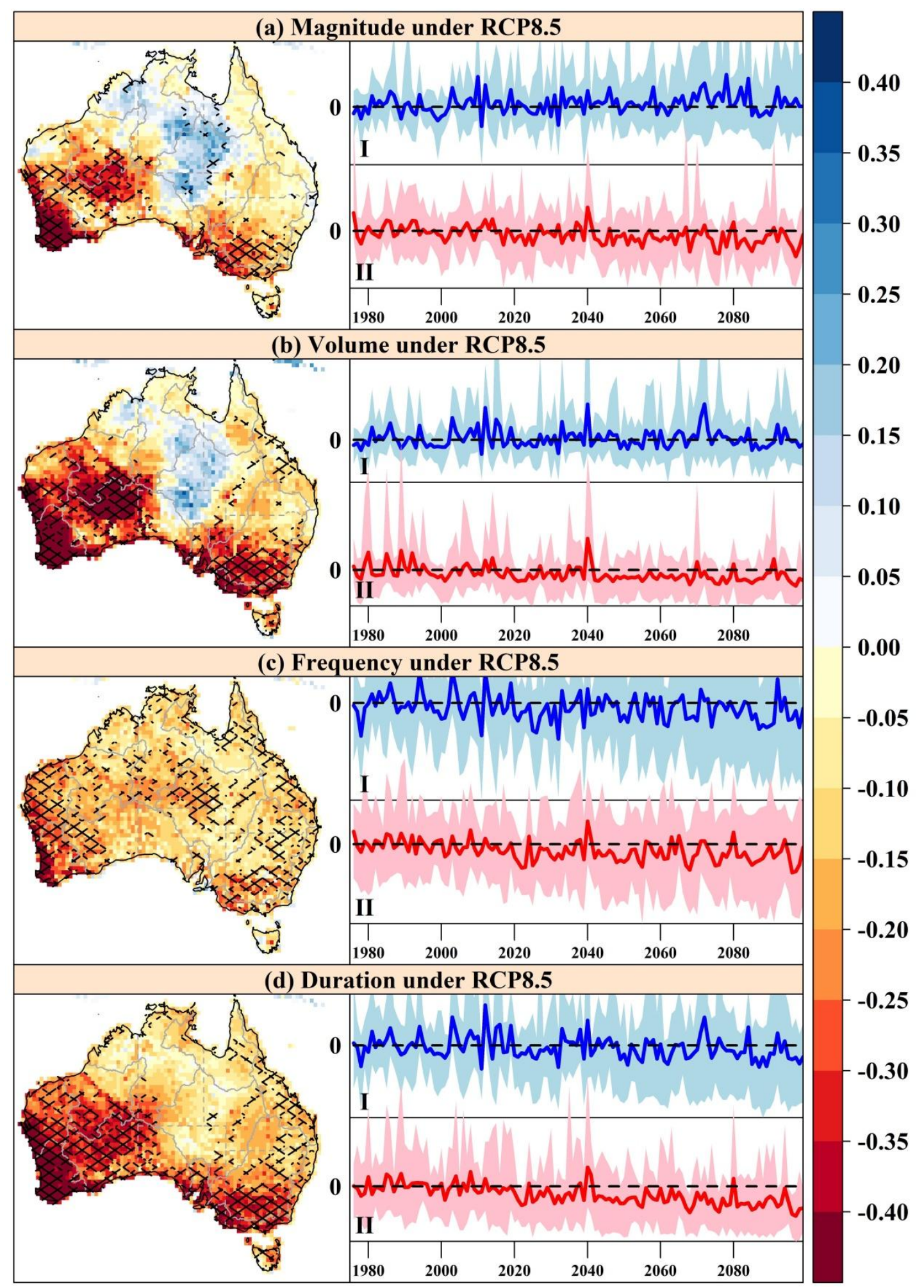

Fig. 12 Multimodel ensemble mean of normalized changes in flood properties across Australia over 2070-2099 under RCP8.5 relative to 1976-2005 under historical scenario (left panels), and the anomalies in multimodel ensemble mean of regional averages over the equatorial and tropical (I) and temperate (II) areas during 1976-2099 (right panels). In the left panels, the areas with black lines indicate more than $60 \%$ of the 40 models agree with the results of multimodel ensemble mean. In the right panels, the colored shadows are the 5-95\% ranges of the corresponding regional averages. 
Table 1 Statistical summary of the catchment attributes in each region

\begin{tabular}{ccccccccc}
\hline Regions & $\begin{array}{c}\text { Number of } \\
\text { catchments }\end{array}$ & $\begin{array}{c}\text { Mean area } \\
\left(\mathrm{km}^{2}\right)\end{array}$ & $\begin{array}{c}\text { Mean } \\
\text { slope }\end{array}$ & $\begin{array}{c}\text { Irrigation ratio } \\
(\%)\end{array}$ & $\begin{array}{c}\text { Intensive } \\
\text { ratio }(\%)\end{array}$ & $\begin{array}{c}\text { Forest } \\
\text { ratio (\%) }\end{array}$ & $\begin{array}{c}\text { Mean precipitation } \\
(\mathrm{mm})\end{array}$ & $\begin{array}{c}\text { Aridity } \\
\text { index }\end{array}$ \\
\hline Equatorial & 7 & 1263.60 & 1.12 & 0.00 & 0.00 & 0.20 & 1582.66 & 1.29 \\
Tropical & 77 & 4041.51 & 3.46 & 0.40 & 0.50 & 0.28 & 1371.09 & 1.64 \\
Subtropical & 100 & 1705.91 & 4.32 & 1.16 & 1.45 & 0.48 & 1025.37 & 1.88 \\
Temperate & 531 & 568.66 & 4.82 & 0.59 & 1.14 & 0.55 & 924.75 & 1.47 \\
Grassland & 51 & 8523.78 & 1.73 & 0.05 & 0.36 & 0.11 & 542.34 & 3.61 \\
Desert & 14 & 15046.62 & 1.42 & 0.00 & 0.08 & 0.04 & 309.48 & 5.60 \\
\hline
\end{tabular}


Table 2 Detail information for the five GCMs from CMIP5

\begin{tabular}{ccc}
\hline GCM & Institution & Resolution (number of grids) \\
\hline GFDL-ESM2M & Geophysical Fluid Dynamics Laboratory & $144 \times 90$ \\
HadGEM2-ES & Met Office Hadley Centre & $192 \times 145$ \\
IPSL-CM5A-LR & L'Institut Pierre-Simon Laplace & $96 \times 96$ \\
& Japan Agency for Marine-Earth Science and Technology, \\
MIROC-ESM-CHEM & Atmosphere and Ocean Research Institute (The University of Tokyo), & $128 \times 64$ \\
& and National Institute for Environmental Studies & $144 \times 96$ \\
\hline
\end{tabular}


Table 3 Main characteristics of the Hydrology models used in this study

\begin{tabular}{|c|c|c|c|c|c|c|c|c|}
\hline Model name & $\begin{array}{l}\text { Time } \\
\text { step }\end{array}$ & $\begin{array}{l}\text { Meteorological } \\
\text { forcing variables }\end{array}$ & $\begin{array}{l}\text { Energy } \\
\text { Balance }\end{array}$ & $\begin{array}{l}\text { Evapo-s } \\
\text { cheme }\end{array}$ & Runoff scheme & $\begin{array}{l}\text { Vegetation } \\
\text { dynamics }\end{array}$ & $\begin{array}{l}\mathrm{CO}_{2} \\
\text { effect }\end{array}$ & References \\
\hline $\begin{array}{c}\text { Distributed } \\
\text { biosphere } \\
\text { hydrological } \\
\text { model (DBH) }\end{array}$ & $1 \mathrm{~h}$ & $\begin{array}{l}\text { P, S, T, W, Q, } \\
\text { LW, SW, SP }\end{array}$ & Yes & $\begin{array}{l}\text { Penman } \\
\text {-Montei } \\
\text { th }\end{array}$ & $\begin{array}{c}\text { Saturation } \\
\text { excess, nonlinear }\end{array}$ & No & No & $\begin{array}{c}\text { Tang et al., } \\
2006\end{array}$ \\
\hline H08 & Daily & $\begin{array}{l}\text { R, S, T, W, Q, } \\
\text { LW, SW, SP }\end{array}$ & Yes & $\begin{array}{c}\text { Bulk } \\
\text { formula }\end{array}$ & $\begin{array}{c}\text { Saturation } \\
\text { excess, nonlinear }\end{array}$ & No & No & $\begin{array}{l}\text { Hanasaki } \\
\text { et al., } 2008\end{array}$ \\
\hline $\begin{array}{c}\text { Macro-Scale } \\
\text { Probability-Distrib } \\
\text { uted Moisture } \\
\text { (Mac-PDM) }\end{array}$ & Daily & $\begin{array}{c}\text { R, S, T, W, Q, } \\
\text { LW, SWnet, SP }\end{array}$ & No & $\begin{array}{c}\text { Penman } \\
\text {-Montei } \\
\text { th }\end{array}$ & $\begin{array}{c}\text { Saturation } \\
\text { excess, nonlinear }\end{array}$ & No & No & $\begin{array}{c}\text { Gosling } \\
\text { and Arnell } \\
2011\end{array}$ \\
\hline Minimal Advanced & & & & & & & & \\
\hline $\begin{array}{c}\text { Treatments of } \\
\text { Surface Interaction } \\
\text { and } \\
\text { Runoff } \\
\text { (MATSIRO) }\end{array}$ & $1 \mathrm{~h}$ & $\begin{array}{l}\text { R, S, T, W, Q, } \\
\text { LW, SW, SP }\end{array}$ & No & $\begin{array}{c}\text { Bulk } \\
\text { formula }\end{array}$ & $\begin{array}{c}\text { Infiltration \& } \\
\text { saturation excess, } \\
\text { groundwater }\end{array}$ & No & $\begin{array}{l}\text { Consta } \\
\text { nt (345 } \\
\text { ppm) }\end{array}$ & $\begin{array}{c}\text { Pokhrel et } \\
\text { al., } 2012\end{array}$ \\
\hline $\begin{array}{c}\text { Max Planck } \\
\text { Institute-Hydrolog } \\
\text { y Model } \\
\text { (MPI-HM) }\end{array}$ & Daily & $\begin{array}{l}\text { P, S, T, W, Q, } \\
\text { LW, SW, SP }\end{array}$ & No & $\begin{array}{c}\text { Penman } \\
\text {-Montei } \\
\text { th }\end{array}$ & $\begin{array}{c}\text { Saturation } \\
\text { excess, nonlinear }\end{array}$ & No & No & $\begin{array}{c}\text { Hagemann } \\
\text { and Gates } \\
2003\end{array}$ \\
\hline $\begin{array}{l}\text { PCRaster Global } \\
\text { Water Balance } \\
\text { (PCR-GLOBWB) }\end{array}$ & Daily & $\mathrm{P}, \mathrm{T}$ & No & Hamon & $\begin{array}{c}\text { Infiltration \& } \\
\text { saturation excess, } \\
\text { groundwater }\end{array}$ & No & No & $\begin{array}{c}\text { Bierkens } \\
\text { and van } \\
\text { Beek } 2009\end{array}$ \\
\hline $\begin{array}{c}\text { Variable } \\
\text { Infiltration } \\
\text { Capacity (VIC) }\end{array}$ & $\begin{array}{l}\text { Daily } \\
\text { /3h }\end{array}$ & $\begin{array}{l}\text { P, Tmax, Tmin, } \\
\text { W, Q, LW, SW, } \\
\text { SP }\end{array}$ & No & $\begin{array}{l}\text { Penman } \\
\text {-Montei } \\
\text { th }\end{array}$ & $\begin{array}{l}\text { Saturation } \\
\text { excess/beta } \\
\text { function }\end{array}$ & No & No & $\begin{array}{l}\text { Liang et } \\
\text { al., } 1994\end{array}$ \\
\hline $\begin{array}{l}\text { Water balance } \\
\text { model (WBM) }\end{array}$ & Daily & $\mathrm{P}, \mathrm{T}$ & No & Hamon & Saturation excess & No & No & $\begin{array}{c}\text { Vörösmart } \\
\text { y et al., } \\
1998\end{array}$ \\
\hline
\end{tabular}

Note: $\mathrm{R}=$ rainfall rate; $\mathrm{S}=$ snowfall rate; $\mathrm{P}=$ precipitation (rain or snow distinguished in the model); $\mathrm{T}$ = air temperature; $\mathrm{W}=$ wind speed $\mathrm{Q}=$ specific humidity; $\mathrm{LW}=$ longwave radiation flux (downward); LWnet = longwave radiation flux (net); $\mathrm{SW}=$ shortwave radiation flux (downward); and SP = surface pressure. Bulk formula: Bulk transfer coefficients are used when calculating the turbulent heat fluxes. Beta function: Runoff is a nonlinear function of soil moisture. 

Supplementary material for on-line publication only
Click here to download Supplementary material for o Click here to download Supplementary material for on-line publication only: Supporting Information.docx 